\title{
Intervenciones en violencia de género en pareja: Artículo de Revisión de la Literatura
}

Interventions on intimate partner violence: A Literture Review Article

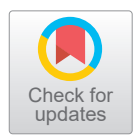

Intervenções sobre a violência entre parceiros íntimos: Uma Artigo da Revisão da Literatura

Como citar este artículo:

Salas-Cubillos Nathaly, García Charry Viviana C, Zapata-Losada Leydy V, Díaz-Usme Olga S. Intervenciones en violencia de género en pareja: Artículo de Revisión de la Literatura. Revista Cuidarte. 2020;11(3):e980.

http://dx.doi.org/10.15649/cuidarte.980

Revista Cuidarte

Rev Cuid. Sept. - Dic. 2020; 11(3): e980

doi) http://dx.doi.org/10.15649/cuidarte.980

E-ISSN: 2346-3414

(1) Nathaly Salas Cubillos ${ }^{1}$

(1) Viviana Carolina García Charry ${ }^{2}$

(1) Leydy Vanesa Zapata Losada ${ }^{3}$

(1) Olga Stella Díaz Usme ${ }^{4}$

1 Universidad El Bosque; Bogotá; Colombia. E-mail nsalasc@unbosque.edu.co; Autor de Correspondencia.

2 Universidad El Bosque; Bogotá; Colombia. E-mail vgarciac@unbosque.edu.co;

3 Universidad El Bosque: Bogotá; Colombia. E-mail Izapatal@unbosque.edu.co

4 Universidad El Bosque; Bogotá - Colombia. E-mail diazolga@ unbosque.edu.co.

\section{Resumen}

Introducción: La violencia es reconocida, como problemática de salud pública. La Organización Mundial de la Salud señala que una de cada tres mujeres ha sido víctima de violencia y que esta se presenta al interior del hogar siendo ejercida en la mayoría de los casos por la pareja o ex pareja, se alude a la violencia de género al interior de la relación de pareja, propósito de esta revisión. Materiales y Métodos: Revisión de la literatura según criterios del Joanna Briggs Institute, con el objetivo de sintetizarel conocimiento relacionado con los tipos de intervención reportados. Se realizó la búsqueda con términos normalizados en bases de datos indexadas periodo 2010 a 2019, que arrojo 103 artículos. Posterior al análisis de criterios de calidad según metodología Critical Appraisal Skills Programme Español Resultados: Se seleccionaron 24 originados en Europa, Latinoamérica y África. Reportan principalmente intervenciones a nivel de psicoeducación desde la perspectiva de género y el modelo piramidal realizadas con hombres, mujeres víctimas y parejas adultas, así como con adolescentes y profesionales. La psico educación se orientó a reflexionar sobre las creencias culturalmente asociadas a los roles de género Conclusiones: Se resalta la efectividad de las intervenciones a nivel de prevención y como principales limitaciones se describe el seguimiento y la dificultad para realizar intervenciones con la pareja, lo cual plantea interrogantes acerca del reconocimiento de las dinámicas de violencia en la pareja y su red de apoyo.

Palabras clave: Violencia de Género; Violencia de Pareja; Prevención Primaria; Evaluación de Resultados de Intervenciones Terapéuticas.

Recibido: septiembre 7 de 2019 Aceptado: mayo 28 de 2020

Publicado: septiembre 1 de 2020 $\square{ }^{*}$ Correspondencia Nathaly Salas Cubillos

E-mail:nsalasc@unbosque.edu.co 


\title{
Interventions on intimate partner violence: A Literature Review
}

\begin{abstract}
Introduction: Intimate partner violence is recognized as a public health problem. The World Health Organization reports that one out of three women has been a victim of intimate partner violence in the home, being mostly perpetrated by a current or former intimate partner. This type of violence is referred to as intimate partner violence, which is the purpose of this review. Materials and Methods: A literature review was conducted following the Joanna Brigs Institute's criteria to synthesize knowledge on the intervention type reported so far. A search was conducted using standardized terms in indexed databases between 2010 and 2019, returning 103 articles after applying the quality criteria analysis according to the Critical Appraisal Skills Programme methodology in Spanish. Results: 24 articles from Europe, Latin America and Africa were selected, in which gender-based psychoeducational interventions have been mainly reported as well as the pyramid model made with men, women victims and adult couples, also adolescents and professionals. Psychoeducation was aimed to reflect on cultural beliefs associated with gender roles. Conclusions: The effectiveness of prevention interventions is evident. Follow-up on couple interventions and their implementation are reported to be the main limitations, which raises questions about the recognition of intimate partner violence dynamics and support network.
\end{abstract}

Key words: Gender-based Violence; Intimate Partner Violence; Primary Prevention; Evaluation of Results of Therapeutic Interventions.

\section{Intervenções sobre a violência entre parceiros íntimos: Uma Revisão da Literatura}

\section{Resumen}

Introdução: A violência entre parceiros íntimos é reconhecida como um problema de saúde pública. A Organização Mundial da Saúde informa que uma de cada três mulheres foi vítima de violência por parceiro íntimo no lar, sendo a maioria perpetrada por um atual ou antigo parceiro íntimo. Este tipo de violência é chamado de violência do parceiro íntimo, que é o objetivo desta revisão. Materiais e Métodos: Uma revisão bibliográfica foi realizada seguindo os critérios do Instituto Joanna Brigs para sintetizar o conhecimento sobre o tipo de intervenção relatado até o momento. Foi realizada uma pesquisa usando termos padronizados em bancos de dados indexados entre 2010 e 2019, retornando 103 artigos após a aplicação da análise dos critérios de qualidade de acordo com a metodologia do Programa de Habilidades de Avaliação Crítica em espanhol. Resultados: 24 artigos da Europa, América Latina e África foram selecionados, nos quais intervenções psico-educacionais baseadas no gênero foram relatadas principalmente, bem como o modelo piramidal feito com homens, mulheres vítimas e casais adultos, também adolescentes e profissionais. A psicoeducação teve como objetivo refletir sobre as crenças culturais associadas aos papéis de gênero. Conclusões: A eficácia das intervenções de prevenção é evidente. O acompanhamento das intervenções de casal e sua implementação são relatados como as principais limitações, o que levanta questões sobre o reconhecimento da dinâmica da violência por parceiro íntimo e da rede de apoio.

Palavras chave: Violência de Gênero; Violência por Parceiro Íntimo; Prevenção Primária; Avaliação de Resultados de Intervenções Terapêuticas. 


\section{Introducción}

La violencia contra la mujer denominada violencia de género, es reconocida como una problemática de salud pública a nivel mundial que evidencia relaciones de poder históricamente desiguales entre el hombre y la mujer ${ }^{1,2}$. La Oficina del Alto Comisionado para los Derechos Humanos (ACNUDH) de la Organización de las Naciones Unidas (ONU), en la Declaración sobre la eliminación de la violencia contra la mujer, la define como "todo acto de violencia basado en la pertenencia al sexo femenino que tenga o pueda tener como resultado un daño o sufrimiento físico, sexual o psicológico para la mujer, así como las amenazas de tales actos, la coacción o la privación arbitraria de la libertad, tanto si se producen en la vida pública como en la vida priva$\mathrm{da}^{\prime \prime}$. Es claro que tanto la perpetración, como la coacción y la amenaza se consideran violencia y que cabe considerar también la negligencia y el abandono como expresiones de violencia ${ }^{4}$. Solo hasta mediados del siglo XX con la creación de La Comisión de la Condición Jurídica y Social de la Mujer se inicia el camino de reconocimiento de los derechos de las mujeres alrededor del mundo y se reconoce la violencia de género como una práctica culturalmente validada, que vulnera estos derechos ${ }^{5}$.

Esta violación a los derechos humanos ha sido históricamente tolerada, silenciada y en la mayoría de culturas justificada desde valores que perpetúan un modelo patriarcal, hegemónico, androcéntrico que deslegitima los derechos de la mujer. El informe de Amnistía Internacional, señala que las mujeres y las niñas continúan sometidas a una amplia gama de abusos que muchos casos se mantienen en la impunidad y que durante el proceso de denuncia, la mujer es revictimizada de múltiples maneras $^{6}$. En países inmersos en conflicto armado la situación se torna aún más crítica.

Los efectos de la violencia de género perduran en el tiempo, se hacen extensivos a los miembros del grupo familiar y se presentan tanto en la esfera pública como privada7. La Organización Panamericana de la Salud - OPS, identifica a la pareja o expareja sentimental como el principal agresor y evidencia, que el hogar es el lugar en el que las mujeres corren mayor

Esta violación a los derechos humanos ha sido históricamente tolerada, silenciada y en la mayoría de culturas justificada desde valores que perpetúan un modelo patriarcal, hegemónico, androcéntrico que deslegitima los derechos de la mujer. riesgo de experimentar la violencia ${ }^{8}$. Sobre la violencia de género asociada a relaciones de pareja se centra la atención de esta revisión.

La Organización Mundial de la Salud (OMS) indica que 35\% de las mujeres del mundo entero ha sido víctima de violencia física y sexual por parte de su pareja, que, en su mayoría se trata de casos de violencia conyugal, y afirma que el $30 \%$ de todas las mujeres que han mantenido una relación de pareja, han sido víctimas de violencia y que en algunas regiones esta cifra alcanza el $38 \%{ }^{9}$. Este organismo hace un llamado a que tanto los estados como las comunidades aporten a la generación de estrategias orientadas a atenuarla. El sector salud debe adoptar un papel decisivo a nivel de prevención de la violencia contra la mujer y comprometerse en la gestión de acciones que aseguren el tratamiento requerido. Señala el organismo internacional que se requiere de una respuesta integral ante esta problemática ${ }^{10}$. Aportar elementos de reflexión y análisis frente a este llamado es uno de los propósitos de la revisión.

Las víctimas de esta violencia presentan múltiples alteraciones en su salud a nivel físico y mental, así como como deterioro en su auto concepto y limitaciones en su interacción social ${ }^{11.12}$, por lo que se reconoce como situación compleja de expresión multidimensional, prioridad en salud pública $^{13}$. Además, debido a los graves efectos que tiene en el desarrollo de las comunidades 
es reconocida como prioridad en el marco de los Objetivos de Desarrollo Sostenible, específicamente el quinto objetivo que hace referencia a la igualdad de género, como pilar fundamental para garantizar el goce efectivo de los derechos de las mujeres y las niñas y eliminar cualquier tipo de maltrato ${ }^{14}$.

En Colombia, esta situación no difiere del contexto internacional. El Instituto Nacional de Medicina Legal y Ciencias Forenses reportó 35.840 casos de violencia intrafamiliar de enero a junio del 2019 , de los cuales 22.866 son violencias ocasionadas por la pareja y en donde el $85.68 \%$ las víctimas son mujeres ${ }^{15}$. Se requiere atención inmediata del sector salud no sólo a nivel de prevención y psicoeducación, sino también del desarrollo de habilidades en el personal de salud para la gestión, desarrollo de programas y estrategias de atención, intervención y seguimiento.

Al abordar la temática, la literatura es amplia en el análisis de factores de riesgo asociados a su presentación en la relación de pareja, entre los que se destacan el consumo de alcohol y sustancias psicoactivas, la historia previa de violencia a nivel familiar, la dependencia económica y emocional ${ }^{16,17}$. Desde una perspectiva ecológica, múltiples estudios valoran y analizan sus efectos tanto en la mujer como en la familia y la comunidad en general, haciendo referencia a un impacto a nivel de macrosistema, exosistema, microsistema, ontogenético y resaltan la importancia de incluir en los protocolos de atención a la mujer ${ }^{18,19}$. En el uso de instrumentos de valoración del riesgo de violencia, se destaca la recomendación de la Guía de evaluación del riesgo de agresión conyugal SARA en inglés The Spousal Assault Risk Assessment, y la combinación de pruebas de personalidad y de vinculación parental, que proporcionan una validez diagnostica de la situación y la inclusión como área de exploración en la entrevista o anamnesis ${ }^{20,21}$.

A nivel de psicoeducación y sensibilización para la prevención de la violencia, los estudios se centran en la población adolescente ${ }^{22,23}$,señalan factores culturales relacionados con la violencia asociados a los paradigmas de masculinidad y feminidad y los analizan a la luz de perspectivas teóricas como el enfoque de género y el modelo ecológico ${ }^{24,25}$.

El objetivo de esta revisión es identificar y analizar las dimensiones desde las que se abordan las intervenciones en la violencia de género en la relación de pareja, reportadas en la literatura entre el 2010 y el 2019.

\section{Materiales y métodos}

Con el objetivo de identificar las intervenciones en violencia de género en las relaciones de pareja, se realizó una revisión de la literatura del año 2010 al 2019; se toma en razón a que en el año 2010 la Organización de las Naciones Unidas promulgó el Manual de Legislación sobre la Violencia contra la Mujer, documento que presenta lineamientos que orientan a los Estados en la formulación de leyes que protejan a las mujeres y constituye un referente importante en el reconocimiento de esta situación como una vulneración a los derechos humanos ${ }^{26}$. Se realizó la búsqueda en las bases de datos PUBMED, SCIELO, DIALNET, REDALYC, ELSIEVER, MEDLINE y en la Biblioteca de Virtual de la Organización Mundial de la Salud y la Organización Panamericana de la Salud, incluyendo Google Académico. La ecuación de búsqueda incluyó los términos normalizados según el DeCS y los operadores booleanos OR y AND con la siguiente estructura: violencia de género Gender-Based Violence OR violencia de pareja/ Intimate Partner Violence" AND Salud /Health AND evaluación de resultados de intervenciones terapéuticas/ evaluation of results of therapeutic interventions. La última revisión de literatura se realizó en agosto de 2019. Para la selección inicial se tomaron los siguientes criterios de inclusión: artículos originales derivados de investigación en diferentes tipos de diseño, disponibles en texto completo que des- 
criban intervenciones frente a la violencia de género en el contexto de la relación de pareja o evaluación de las mismas, que el sujeto de interés sea uno de los miembros de la pareja, que no abordará el tema en gestantes ni asociaran su presencia al consumo de sustancias psicoactivas o alcohol.

Los criterios de exclusión se identifican en cada uno de los filtros, como se observa en el diagrama de flujo (Ver Figura 1). Se recuperaron 432 estudios, se excluyeron 329 artículos por las siguientes razones: a) hacían referencia a programas, b) tesis doctorales y actas de congresos, c) duplicados, d) datos insuficientes para obtener información pertinente, e) enfocadas a procedimiento judicial frente a casos de violencia doméstica. En esta etapa fueron seleccionados 103 estudios.

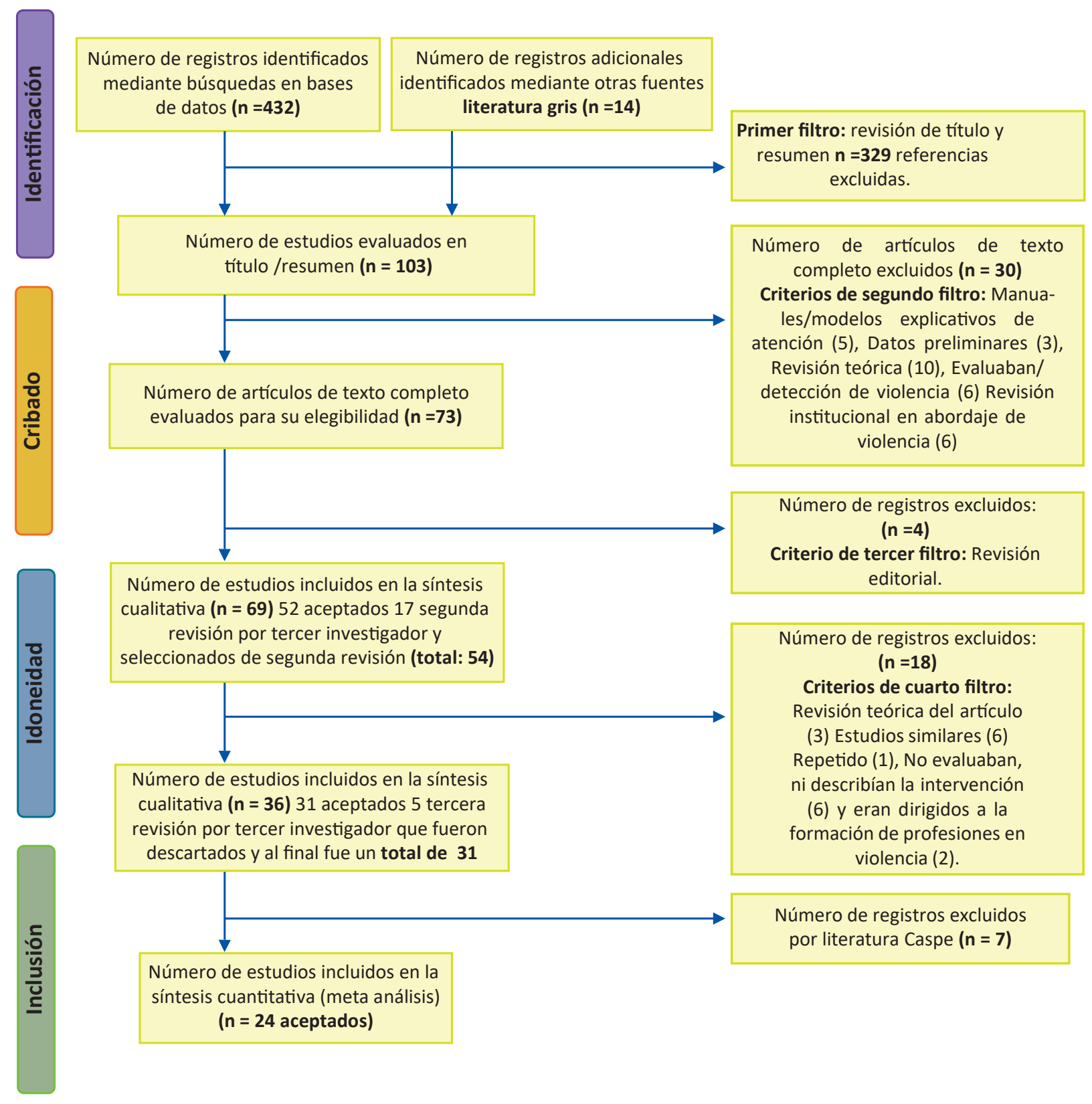

Figura 1. Diagrama de flujo metodología revisión bibliográfica violencia de pareja 2010-2019 Fuente elaboración propia

Posteriormente dos miembros del grupo de investigadores evaluaron los documentos de manera independiente y en caso de discrepancias, se realizaba una revisión por el tercer inves- 
tigador. El porcentaje de acuerdo fue de un $70 \%$. Una vez se eliminaron los estudios que no cumplieron criterios, se procedió al segundo filtro, evaluando por resumen y título de los 103 artículos, siendo excluidos un total de 30 estudios por los siguientes criterios: 5 correspondían a manuales y modelos explicativos de atención violencia, 3 presentaban datos preliminares, 10 eran revisión teórica de violencia de género, 6 evaluaban detección de violencia de género y 6 revisiones institucionales en el abordaje de violencia. Los 73 estudios restantes fueron evaluados para elegibilidad, en el que se aplicó el tercer filtro y fueron excluidos 4 artículos de revisión editorial.

Los 69 estudios resultantes, se sometieron a una revisión de síntesis cualitativa, donde inicialmente 52 estudios fueron incluidos y 17 fueron sometidos a una segunda revisión por parte del tercer investigador, incluyendo 2 artículos que fueron aceptados, para un total de 54. En un cuarto filtro, se descartaron 18 artículos 3 de ellos se incluyeron en otros apartes del artículo, como revisión teórica, justificación y discusión, haciendo parte de la literatura gris, 6 estudios se descartaron por ser reelaboraciones de otro, 1 que estaba repetido, 2 que estaban enfocados a la formación de profesionales para intervenciones de violencia de género y 6 que no evaluaban ni describían la intervención.

En la última síntesis cualitativa, se descartaron 5 artículos con discrepancias, por lo cual los 31 artículos restantes, se sometieron a la herramienta de análisis, el instrumento de lectura crítica de Critical Appraisal Skills Programme (CASpe) para revisión sistemática, estudios cualitativos, cuantitativos y mixtos. Se excluyeron 7 artículos que estaban por debajo del porcentaje requerido de $70 \%$ de esta herramienta. Finalmente, el insumo investigativo para la realización de la revisión bibliográfica fueron los 24 estudios restantes, los cuales se incluyeron en la síntesis cuantitativa y meta análisis a través de la ficha de extracción de datos.

Los documentos seleccionados son la muestra que sirve de base a la revisión, orientada según los lineamientos del Joanna Briggs Institute, que describe que frente a problemáticas relacionados con la salud pública que brinden orientaciones frente a temas de política social es viable incluir estudios derivados de diversas metodologías incluidas revisiones previas ${ }^{27}$. En el proceso de análisis se abordaron los objetivos específicos de la reflexión metodológica de enfoque y las limitaciones metodológicas que se presentan en el abordaje de las intervenciones en violencia de pareja. La totalidad de los documentos fueron referenciados dando cumplimiento a la normatividad nacional respecto a derechos de autor: Ley 915 del 12 de julio 2018.

Las autoras manifiestan no tener conflicto de intereses

\section{Resultados}

La presentación de los resultados se realiza tomando en cuenta inicialmente la caracterización de la totalidad de estudios, con el propósito de presentar un análisis homogéneo de los mismos, un segundo momento describe los aspectos que se evidencian en algunos y que aportan a la identificación de las dimensiones desde las que se realizan las intervenciones en violencia de género en el contexto de la relación de pareja.

\section{Características de las intervenciones reportadas en los estudios}

De los 24 estudios primarios escogidos (Ver cuadro 1), se identificó que el mayor rango de publicaciones se presentó entre el 2013 y 2016, con un total de 15 estudios ${ }^{27-41}$. España, es el país con mayor cantidad de publicaciones ${ }^{28-33,36,37,41-44}$, Brasil ${ }^{37,38}$, Chile $^{45}$, Colombia $27,39,46,47$, Ecuador ${ }^{48}$, 
México ${ }^{40}$ reportan investigaciones y dos del continente africano, Uganda ${ }^{35}$ y Costa de Marfil ${ }^{34}$. Se evidencia interés por el abordaje de esta temática especialmente en Hispanoamérica.

Las revisiones sistemáticas, descriptivas e integrativas recuperadas $38-41,43,44$, se orientan a analizar las experiencias de intervenciones con hombres maltratadores $40,41,43,44$, adolescentes y jóvenes $^{38,39}$. Se recuperaron y analizaron nueve estudios cuantitativos, tres de tipo experimental $^{33,37,49}$, cuasi experimentales $9,30-32$, ensayo controlado y aleatorizado ${ }^{34,35}$, enfocados en evaluar la eficacia e impacto de dichas intervenciones tomando como criterios de evaluación estrategias de cambio, técnicas cognitivo conductuales e instrumentos que permitían identificar las variables de los estudios para su análisis.

Los estudios cualitativos fueron cinco, con enfoque fenomenológico, estudios de caso y exploratorio ${ }^{27-29,42,46}$, centrados en presentar la problemática como un fenómeno social a través del significado de las experiencias y comportamientos de las personas que lo viven en un contexto $^{28}$. Los estudios mixtos fueron cuatro $36,45,47,48$, resaltan la evaluación del impacto de las intervenciones, especialmente de prevalencia, hacen énfasis en la flexibilidad para ampliar los resultados del impacto a través de un análisis descriptivo.

\section{Cuadro 1. Tipo de estudio y participación, población, modalidad y nivel de intervenciones violencia de pareja 2010-2019}

\begin{tabular}{|c|c|c|c|c|c|c|c|c|}
\hline & $\begin{array}{c}\text { Título del } \\
\text { articulo }\end{array}$ & $\begin{array}{l}\text { País } \\
\text { año }\end{array}$ & $\% *$ & Tipo de estudio & $\begin{array}{c}\text { Población } \\
\text { diana }\end{array}$ & $\begin{array}{c}\text { Tipo de } \\
\text { participación }\end{array}$ & $\begin{array}{l}\text { Modalidad } \\
\text { intervención }\end{array}$ & $\begin{array}{c}\text { Nivel de } \\
\text { intervención }\end{array}$ \\
\hline 1 & $\begin{array}{l}\text { Preventing violence } \\
\text { by intimate partners } \\
\text { in adolescence: an } \\
\text { integrative review }\end{array}$ & $\begin{array}{l}\text { Brasil } \\
2015\end{array}$ & 70 & $\begin{array}{l}\text { Revisión } \\
\text { integrativa de } \\
\text { literatura }\end{array}$ & Adolescentes & $\begin{array}{l}\text { Vinculados por } \\
\text { normatividad } \\
\text { institucional } \\
\text { (institución } \\
\text { educativa) }\end{array}$ & Grupales & Prevención \\
\hline & $\begin{array}{l}\text { Evaluation of the } \\
\text { Impact of a } \\
\text { Cognitive } \\
\text { Behavioral } \\
\text { Intervention for } \\
\text { Women in } \\
\text { Domestic Violence } \\
\text { Situations in Brazil }\end{array}$ & $\begin{array}{l}\text { Brasil } \\
2018\end{array}$ & 90 & $\begin{array}{l}\text { Cuantitativo } \\
\text { cuasi } \\
\text { experimental }\end{array}$ & $\begin{array}{l}\text { Mujeres } \\
\text { víctimas de } \\
\text { violencia }\end{array}$ & $\begin{array}{l}\text { Referidas por } \\
\text { centro de atención } \\
\text { para mujeres } \\
\text { víctimas }\end{array}$ & Individual & $\begin{array}{l}\text { Tratamiento y } \\
\text { prevención de } \\
\text { recaídas }\end{array}$ \\
\hline 3 & $\begin{array}{l}\text { La Cuarta R: Un } \\
\text { programa escolar de } \\
\text { prevención de la } \\
\text { violencia en las } \\
\text { relaciones de pareja } \\
\text { en la adolescencia. }\end{array}$ & $\begin{array}{c}\text { Canadá } \\
2011\end{array}$ & 90 & $\begin{array}{l}\text { Cuantitativo - } \\
\text { Diseño } \\
\text { experimental }\end{array}$ & $\begin{array}{l}\text { Adolescentes } \\
14 \text { y } 15 \text { años }\end{array}$ & $\begin{array}{l}\text { Vinculación } \\
\text { voluntaria - } \\
\text { Institucional }\end{array}$ & $\begin{array}{c}\text { Individuales y } \\
\text { grupales }\end{array}$ & Prevención \\
\hline 4 & $\begin{array}{l}\text { Diseño, } \\
\text { Implementación y } \\
\text { Evaluación de un } \\
\text { Programa de } \\
\text { Prevención de la } \\
\text { Violencia en el } \\
\text { Noviazgo. }\end{array}$ & $\begin{array}{l}\text { Chile } \\
2011\end{array}$ & 80 & Mixto & $\begin{array}{l}\text { Jóvenes } \\
\text { estudiantes de } \\
\text { educación } \\
\text { superior }\end{array}$ & $\begin{array}{c}\text { Vinculación } \\
\text { Voluntaria }\end{array}$ & Grupales & $\begin{array}{l}\text { Prevención } \\
\text { (Sensibilización, } \\
\text { Educación) }\end{array}$ \\
\hline 5 & $\begin{array}{l}\text { Adaptación de un } \\
\text { programa de } \\
\text { intervención de } \\
\text { intervención para } \\
\text { violencia } \\
\text { situacional de } \\
\text { parejas. }\end{array}$ & $\begin{array}{l}\text { Colombia } \\
2018\end{array}$ & 90 & Cualitativo & $\begin{array}{c}\text { Parejas de } \\
\text { adultos }\end{array}$ & $\begin{array}{c}\text { Vinculación } \\
\text { Voluntaria }\end{array}$ & $\begin{array}{c}\text { Grupal en } \\
\text { pareja }\end{array}$ & $\begin{array}{l}\text { Intervención y } \\
\text { Tratamiento }\end{array}$ \\
\hline
\end{tabular}




\begin{tabular}{|c|c|c|c|c|c|c|c|}
\hline $\begin{array}{l}\text { Título del } \\
\text { articulo }\end{array}$ & $\begin{array}{l}\text { País } \\
\text { año }\end{array}$ & $\% *$ & Tipo de estudio & $\begin{array}{l}\text { Población } \\
\text { diana }\end{array}$ & $\begin{array}{c}\text { Tipo de } \\
\text { participación }\end{array}$ & $\begin{array}{l}\text { Modalidad } \\
\text { intervención }\end{array}$ & $\begin{array}{c}\text { Nivel de } \\
\text { intervención }\end{array}$ \\
\hline $\begin{array}{l}6 \text { Prevención de } \\
\text { violencia en el } \\
\text { noviazgo: una } \\
\text { revisión de } \\
\text { programas } \\
\text { publicados entre } \\
1990 \text { y } 2012 .\end{array}$ & $\begin{array}{l}\text { Colombia } \\
2013\end{array}$ & 80 & $\begin{array}{l}\text { Revisión } \\
\text { sistemática }\end{array}$ & $\begin{array}{l}\text { Adolescentes } \\
\text { y jóvenes de } \\
\text { educación } \\
\text { secundaria y } \\
\text { superior }\end{array}$ & $\begin{array}{l}\text { Vinculación } \\
\text { Voluntaria }\end{array}$ & Grupales & $\begin{array}{c}\text { Prevención } \\
\text { primaria/ } \\
\text { pedagógico }\end{array}$ \\
\hline $\begin{array}{l}7 \text { Efecto de una } \\
\text { intervención } \\
\text { cognoscitivo } \\
\text { conductual para el } \\
\text { manejo de los celos } \\
\text { en la relación de } \\
\text { pareja. }\end{array}$ & $\begin{array}{l}\text { Colombia } \\
2015\end{array}$ & 90 & $\begin{array}{l}\text { Cualitativa - } \\
\text { estudios de } \\
\text { caso }\end{array}$ & $\begin{array}{c}\text { Mujeres, } \\
\text { estudiantes } \\
\text { universitarias }\end{array}$ & $\begin{array}{c}\text { Vinculación } \\
\text { Voluntaria }\end{array}$ & $\begin{array}{c}\text { Individuales } \\
\text { Grupales - } \\
\text { pareja }\end{array}$ & $\begin{array}{l}\text { Tratamiento y } \\
\text { Educación }\end{array}$ \\
\hline $\begin{array}{l}8 \text { Como marcar tres } \\
\text { dígitos reduce la } \\
\text { violencia íntima de } \\
\text { pareja en Medellín, } \\
\text { Colombia. } \\
\text { Evaluación del } \\
\text { impacto de la línea } \\
\text { de emergencia } 123 \\
\text { Mujer, } 2013 \text { - } 2014 .\end{array}$ & $\begin{array}{l}\text { Colombia } \\
2018\end{array}$ & 80 & $\begin{array}{l}\text { Mixto - } \\
\text { estudio de } \\
\text { Cohorte }\end{array}$ & $\begin{array}{l}\text { Mujeres } \\
\text { víctimas de } \\
\text { violencia }\end{array}$ & $\begin{array}{l}\text { Línea de atención } \\
\text { inmediata }\end{array}$ & Individuales & $\begin{array}{l}\text { Atención - } \\
\text { prevención }\end{array}$ \\
\hline $\begin{array}{l}9 \text { Gender norms and } \\
\text { economic } \\
\text { empowerment } \\
\text { intervention to } \\
\text { reduce intimate } \\
\text { partner violence } \\
\text { against women in } \\
\text { rural Côte d'Ivoire: } \\
\text { a randomized } \\
\text { controlled pilot } \\
\text { study. }\end{array}$ & $\begin{array}{c}\text { Costa de } \\
\text { Marfil } \\
2013\end{array}$ & 80 & $\begin{array}{c}\text { Cuantitativo } \\
\text { experimental } \\
\text { (ensayo } \\
\text { controla } \\
\text { aleatorizado) }\end{array}$ & $\begin{array}{l}\text { Parejas de } \\
\text { adultos }\end{array}$ & $\begin{array}{l}\text { Vinculación } \\
\text { Voluntaria }\end{array}$ & $\begin{array}{c}\text { Individual y } \\
\text { grupal }\end{array}$ & $\begin{array}{l}\text { Prevención, } \\
\text { sensibilización, } \\
\text { educación }\end{array}$ \\
\hline $\begin{array}{l}10 \text { Violencia física } \\
\text { contra la mujer: } \\
\text { una propuesta de } \\
\text { abordaje desde un } \\
\text { servicio de salud. }\end{array}$ & $\begin{array}{l}\text { Ecuador } \\
2017\end{array}$ & 90 & $\begin{array}{c}\text { Mixta - } \\
\text { Investigación - } \\
\text { Acción }\end{array}$ & $\begin{array}{l}\text { Personal } \\
\text { de salud y la } \\
\text { comunidad }\end{array}$ & $\begin{array}{c}\text { Vinculación } \\
\text { Voluntaria }\end{array}$ & $\begin{array}{c}\text { Individual y } \\
\text { grupal }\end{array}$ & $\begin{array}{l}\text { Prevención } \\
\text { primaria }\end{array}$ \\
\hline $\begin{array}{l}11 \text { Necesidades } \\
\text { terapéuticas en } \\
\text { agresores de pareja } \\
\text { según su perfil } \\
\text { diferencial. }\end{array}$ & $\begin{array}{c}\text { España } \\
2010\end{array}$ & 70 & $\begin{array}{c}\text { Revisión } \\
\text { sistemática }\end{array}$ & $\begin{array}{c}\text { Hombres } \\
\text { maltratadores }\end{array}$ & $\begin{array}{l}\text { Vinculados por } \\
\text { normatividad } \\
\text { institucional } \\
\text { (orden judicial) }\end{array}$ & $\begin{array}{l}\text { Individuales y } \\
\text { grupales, }\end{array}$ & $\begin{array}{l}\text { Tratamiento y } \\
\text { rehabilitación }\end{array}$ \\
\hline $\begin{array}{l}12 \text { Reeducación de } \\
\text { Maltratadores: Una } \\
\text { Experiencia de } \\
\text { Intervención desde } \\
\text { la Perspectiva de } \\
\text { Género. }\end{array}$ & $\begin{array}{c}\text { España } \\
2010\end{array}$ & 90 & $\begin{array}{c}\text { Revisión } \\
\text { descriptiva }\end{array}$ & $\begin{array}{c}\text { Hombres } \\
\text { maltratadores }\end{array}$ & $\begin{array}{l}\text { Vinculados por } \\
\text { normatividad } \\
\text { institucional } \\
\text { (orden judicial) }\end{array}$ & $\begin{array}{l}\text { Individuales } \\
\text { y grupales, }\end{array}$ & $\begin{array}{l}\text { Rehabilitación / } \\
\text { reeducación }\end{array}$ \\
\hline $\begin{array}{l}13 \text { Una Experiencia de } \\
\text { Investigación, } \\
\text { Formación e } \\
\text { Intervención con } \\
\text { Hombres Penados } \\
\text { por Violencia contra } \\
\text { la Mujer en la } \\
\text { Universidad de } \\
\text { Valencia. }\end{array}$ & $\begin{array}{l}\text { España } \\
2010\end{array}$ & 80 & $\begin{array}{l}\text { Cualitativo } \\
\text { exploratorio }\end{array}$ & $\begin{array}{c}\text { Hombres } \\
\text { maltratadores }\end{array}$ & $\begin{array}{l}\text { Vinculados por } \\
\text { normatividad } \\
\text { institucional } \\
\text { (orden judicial) }\end{array}$ & $\begin{array}{c}\text { Individual y } \\
\text { grupal - } \\
\text { pareja) }\end{array}$ & $\begin{array}{l}\text { Tratamiento y } \\
\text { prevención en } \\
\text { recaídas }\end{array}$ \\
\hline
\end{tabular}




\begin{tabular}{|c|c|c|c|c|c|c|c|}
\hline $\begin{array}{c}\text { Título del } \\
\text { articulo }\end{array}$ & $\begin{array}{l}\text { País } \\
\text { año }\end{array}$ & $\% *$ & Tipo de estudio & $\begin{array}{c}\text { Población } \\
\text { diana }\end{array}$ & $\begin{array}{c}\text { Tipo de } \\
\text { participación }\end{array}$ & $\begin{array}{l}\text { Modalidad } \\
\text { intervención }\end{array}$ & $\begin{array}{c}\text { Nivel de } \\
\text { intervención }\end{array}$ \\
\hline $\begin{array}{l}14 \text { Evaluación de la } \\
\text { eficacia del } \\
\text { programa de } \\
\text { tratamiento con } \\
\text { agresores de pareja } \\
\text { (PRIA) en la } \\
\text { comunidad. }\end{array}$ & $\begin{array}{c}\text { España } \\
2013\end{array}$ & $9 / 10$ & $\begin{array}{l}\text { Cuantitativo } \\
\text { experimental }\end{array}$ & $\begin{array}{l}\text { Hombres } \\
\text { maltratadores }\end{array}$ & $\begin{array}{l}\text { Vinculados por } \\
\text { Normatividad } \\
\text { Institucional } \\
\text { (orden judicial) }\end{array}$ & $\begin{array}{c}\text { Individuales y } \\
\text { grupales }\end{array}$ & $\begin{array}{l}\text { Tratamiento y } \\
\text { Prevención de } \\
\text { recaídas }\end{array}$ \\
\hline $\begin{array}{l}15 \text { El DaViPoP: un } \\
\text { programa de } \\
\text { prevención de } \\
\text { violencia en el } \\
\text { cortejo y las parejas } \\
\text { adolescentes. }\end{array}$ & $\begin{array}{c}\text { España } \\
2013\end{array}$ & 90 & $\begin{array}{l}\text { Mixto cuasi } \\
\text { experimental }\end{array}$ & $\begin{array}{c}\text { Adolescentes } \\
\text { de educación } \\
\text { secundaria }\end{array}$ & $\begin{array}{l}\text { Vinculación } \\
\text { Institucional } \\
\text { Voluntaria }\end{array}$ & Grupales & $\begin{array}{c}\text { Prevención } \\
\text { primaria - } \\
\text { Psicoeducativo }\end{array}$ \\
\hline $\begin{array}{l}16 \text { Intervención en } \\
\text { Mujeres Víctimas } \\
\text { de Violencia de } \\
\text { Género. Experiencia } \\
\text { de Psicoterapia } \\
\text { Grupal en un Centro } \\
\text { de Salud Mental. }\end{array}$ & $\begin{array}{l}\text { España } \\
2014\end{array}$ & 90 & Cualitativo & $\begin{array}{c}\text { Mujeres } \\
\text { víctimas de } \\
\text { violencia }\end{array}$ & $\begin{array}{l}\text { Referidas - por } \\
\text { profesionales en } \\
\text { Salud Mental }\end{array}$ & $\begin{array}{c}\text { Individual } \\
\text { (entrevista } \\
\text { inicial) y } \\
\text { grupales }\end{array}$ & $\begin{array}{c}\text { Tratamiento - } \\
\text { psicoeducación. }\end{array}$ \\
\hline $\begin{array}{l}17 \text { Eficacia de un } \\
\text { programa de } \\
\text { tratamiento } \\
\text { psicológico } \\
\text { individual } \\
\text { para mujeres } \\
\text { maltratadas } \\
\text { por su pareja. }\end{array}$ & $\begin{array}{c}\text { España } \\
2014\end{array}$ & 80 & $\begin{array}{l}\text { Cuantitativo - } \\
\text { Cuasi } \\
\text { experimental }\end{array}$ & $\begin{array}{l}\text { Mujeres } \\
\text { víctimas de } \\
\text { violencia }\end{array}$ & $\begin{array}{l}\text { Solicitaron } \\
\text { atención en } \\
\text { centros de } \\
\text { atención para } \\
\text { víctimas con } \\
\text { diagnóstico } \\
\text { previo }\end{array}$ & $\begin{array}{c}\text { Individuales y } \\
\text { grupal }\end{array}$ & $\begin{array}{l}\text { Tratamiento y } \\
\text { psicoeducativo }\end{array}$ \\
\hline $\begin{array}{l}18 \text { Programa para el } \\
\text { contexto escolar de } \\
\text { prevención de } \\
\text { violencia en } \\
\text { parejas } \\
\text { adolescentes. }\end{array}$ & $\begin{array}{c}\text { España } \\
2015\end{array}$ & 100 & $\begin{array}{l}\text { Cuantitativo - } \\
\text { Experimental }\end{array}$ & Adolescentes & $\begin{array}{l}\text { Vinculación } \\
\text { Voluntaria }\end{array}$ & Grupales & $\begin{array}{l}\text { Prevención y } \\
\text { promoción }\end{array}$ \\
\hline $\begin{array}{l}19 \text { ¿Influyen las } \\
\text { diferencias } \\
\text { culturales en los } \\
\text { resultados de los } \\
\text { programas de } \\
\text { intervención con } \\
\text { maltratadores? Un } \\
\text { estudio con } \\
\text { agresores españoles } \\
\text { y latinoamericanos. }\end{array}$ & $\begin{array}{l}\text { España } \\
2015\end{array}$ & 80 & $\begin{array}{c}\text { Cuantitativa, } \\
\text { Cuasiexperimental. }\end{array}$ & $\begin{array}{c}\text { Hombres } \\
\text { maltratadores }\end{array}$ & $\begin{array}{l}\text { Vinculados por } \\
\text { Normatividad } \\
\text { Institucional } \\
\text { (orden judicial) }\end{array}$ & $\begin{array}{c}\text { Individuales y } \\
\text { grupales }\end{array}$ & $\begin{array}{l}\text { Tratamiento y } \\
\text { rehabilitación }\end{array}$ \\
\hline $\begin{array}{l}20 \text { Eficacia de un } \\
\text { programa de } \\
\text { intervención para } \\
\text { mujeres maltratadas } \\
\text { por su pareja. }\end{array}$ & $\begin{array}{l}\text { España } \\
2016\end{array}$ & 80 & $\begin{array}{c}\text { Cuantitativa, } \\
\text { Cuasiexperimental. }\end{array}$ & $\begin{array}{c}\text { Mujeres } \\
\text { víctimas de } \\
\text { violencia }\end{array}$ & $\begin{array}{l}\text { Solicitaron } \\
\text { atención en } \\
\text { centros de } \\
\text { atención para } \\
\text { víctimas con } \\
\text { diagnóstico previo }\end{array}$ & $\begin{array}{c}\text { Individuales y } \\
\text { grupales }\end{array}$ & $\begin{array}{l}\text { Tratamiento y } \\
\text { Educación. } \\
\text { Rehabilitación }\end{array}$ \\
\hline $\begin{array}{l}21 \text { Programas de } \\
\text { intervención con } \\
\text { maltratadores en } \\
\text { España: la } \\
\text { perspectiva de } \\
\text { los/as profesionales }\end{array}$ & $\begin{array}{c}\text { España } \\
2016\end{array}$ & 80 & $\begin{array}{c}\text { Cualitativa } \\
\text { enfoque } \\
\text { fenomenológico }\end{array}$ & $\begin{array}{l}\text { Profesionales } \\
\text { que trabajaron } \\
\text { con hombres } \\
\text { maltratadores } \\
\text { (pedagogos, } \\
\text { psicólogos, otros) }\end{array}$ & $\begin{array}{l}\text { Vinculación } \\
\text { Voluntaria }\end{array}$ & Individuales. & $\begin{array}{c}\text { Varios } \\
\text { programas de } \\
\text { intervención } \\
\text { Valorado por } \\
\text { los profesionales } \\
\text { que lo ejecutan }\end{array}$ \\
\hline $\begin{array}{l}22 \text { Las Masculinidades } \\
\text { y los Programas de } \\
\text { Intervención para } \\
\text { Maltratadores en } \\
\text { casos de Violencia } \\
\text { de Género en } \\
\text { España. }\end{array}$ & $\begin{array}{l}\text { España } \\
2016\end{array}$ & 80 & $\begin{array}{l}\text { Revisión } \\
\text { sistemática }\end{array}$ & $\begin{array}{c}\text { Hombres } \\
\text { maltratadores }\end{array}$ & $\begin{array}{l}\text { Institucional de } \\
\text { orden judicial } \\
\text { (2 voluntario y } \\
1 \text { requisito) }\end{array}$ & $\begin{array}{c}\text { Individuales, } \\
\text { grupales y de } \\
\text { pareja }\end{array}$ & $\begin{array}{l}\text { Rehabilitación / } \\
\text { reeducación }\end{array}$ \\
\hline
\end{tabular}




\begin{tabular}{|c|c|c|c|c|c|c|c|}
\hline $\begin{array}{c}\text { Título del } \\
\text { articulo }\end{array}$ & $\begin{array}{l}\text { País } \\
\text { año }\end{array}$ & $\% *$ & Tipo de estudio & $\begin{array}{c}\text { Población } \\
\text { diana }\end{array}$ & $\begin{array}{c}\text { Tipo de } \\
\text { participación }\end{array}$ & $\begin{array}{c}\text { Modalidad } \\
\text { intervención }\end{array}$ & $\begin{array}{c}\text { Nivel de } \\
\text { intervención }\end{array}$ \\
\hline $\begin{array}{l}23 \text { Efectividad de las } \\
\text { intervenciones en la } \\
\text { violencia de pareja } \\
\text { y ética. }\end{array}$ & $\begin{array}{l}\text { México } \\
2014\end{array}$ & 90 & $\begin{array}{c}\text { Revisión } \\
\text { sistemática }\end{array}$ & $\begin{array}{l}\text { Hombres } \\
\text { maltratadores }\end{array}$ & $\begin{array}{l}\text { Participación } \\
\text { Voluntaria y } \\
\text { orden judicial }\end{array}$ & $\begin{array}{c}\text { Individuales, } \\
\text { grupales y de } \\
\text { pareja }\end{array}$ & $\begin{array}{l}\text { Tratamiento/ } \\
\text { rehabilitación }\end{array}$ \\
\hline $\begin{array}{l}24 \text { The impact of } \\
\text { SASA!, a } \\
\text { community } \\
\text { mobilisation } \\
\text { intervention, on } \\
\text { women's experience } \\
\text { of intimate partner } \\
\text { violence: secondary } \\
\text { findings from a } \\
\text { cluster randomised } \\
\text { trial in Kampala, } \\
\text { Uganda. }\end{array}$ & $\begin{array}{l}\text { Uganda } \\
2016\end{array}$ & 100 & $\begin{array}{l}\text { Cuantitativo } \\
\text { experimental } \\
\text { (ensayo controla } \\
\text { aleatorizado) }\end{array}$ & $\begin{array}{l}\text { Mujeres } \\
\text { víctimas de } \\
\text { violencia }\end{array}$ & $\begin{array}{l}\text { Vinculación } \\
\text { Voluntaria }\end{array}$ & Grupales & Prevención \\
\hline
\end{tabular}

*Clasificación metodología Critical Appraisal Skills Programme Español -CASPe

\section{Sujetos abordados en las intervenciones}

Se identificaron estudios que reportan intervenciones orientadas a adolescentes de educación secundaria $33,36,38,49$, jóvenes de educación superior ${ }^{45}$, una revisión de jóvenes de educación secundaria y superior $^{39}$, hombres maltratadores ${ }^{30,37,40-44}$, mujeres víctimas de violencia de pareja 9,27,29,31,32,35,47, profesionales de salud ${ }^{48}$, pedagogos, psicólogos, colaboradores que trabajaron con hombres maltratadores ${ }^{43} \mathrm{y}$ dos estudios realizaron intervenciones a parejas ${ }^{34,46}$.

\section{Adolescentes y adultos jóvenes}

Las revisiones que se realizaron con esta población destacan la participación voluntaria y aunque la intervención era incluida en el currículo de las asignaturas y realizada desde la institución, se resalta el interés y motivación de los jóvenes ${ }^{36,49}$; la intervención más exitosa fue la que se proporcionaba como parte del currículo, tenían continuidad, contaba con un número suficiente de sesiones y se orientaba al desarrollo de conocimiento, actitudes y habilidades frente al manejo de esta temática ${ }^{45}$; las escuelas se consideran el lugar ideal para desarrollar este tipo de intervenciones, teniendo en cuenta que la adolescencia es un periodo de la vida especialmente apropiado para prevenir la adopción de pautas relacionales violentas ${ }^{49}$. Éstas se desarrollaban desde la prevención primara con el objetivo de fortalecer habilidades relacionales saludables como parte fundamental de su desarrollo, resaltando que a esa edad la dinámica relacional violenta y abusiva aún no está consolidada ${ }^{36}$. Y además, parten del sustrato teórico donde la violencia con la pareja intervienen factores de riesgo educativo, familiar, social, cultural y personales que pueden ser modificables a través de estrategias de educación en salud ${ }^{33}$.

\section{Hombres maltratadores}

Las intervenciones dirigidas a hombres maltratadores, se articulan a la normatividad y orden judicial especialmente en países como España y México. Sin embargo, también se contempla un componente de voluntariedad, según el tipo diferencial del agresor ${ }^{40,44}$. Las intervenciones hacen una diferenciación de sujetos violentos con la pareja estables emocionalmente e integrados socialmente, con sujetos violentos generalizados, poco estables emocionalmente y no integrados socialmente con características particulares de compulsión o rigidez, dependencia emocional y deseabilidad social que ayuda a la elección de las intervenciones ${ }^{44,43}$. Se identifican 
intervenciones caracterizadas por su elevado nivel de estandarización y por ser objeto de seguimiento y evaluación; otras intervenciones eran de medida penal alternativa para maltratadores condenados a menos de dos años que no ingresaban a prisión, pero estaban obligados judicialmente a participar e intervenciones de asistencia voluntaria, que trabajan con hombres y tienen experiencias en contextos comunitarios, siendo necesario no reportar dependencia a sustancias psicoactivas, no tener diagnóstico psiquiátrico ${ }^{41}$. Los excluidos participaban en intervenciones enfocados en promoción y prevención de recaídas ${ }^{40,41}$.

En esta población, la intervención se orienta al tratamiento, rehabilitación, reeducación y prevención de recaídas ${ }^{40,43}$, evidenciando en la mayoría un cambio después de la intervención, en las características psicológicas, actitudes y distorsiones cognitivas y el uso de la violencia como forma inaceptable de solucionar conflictos ${ }^{37,41,42}$. Además, el tratamiento se enfoca en la motivación para la participación y continuidad en las intervenciones ${ }^{44}$. Las falencias que se evidencian es el limitado acompañamiento de la pareja en el proceso terapéutico, la duración y la falta de seguimiento ${ }^{40}$.

\section{Mujeres víctimas de violencia de pareja}

Las intervenciones orientadas a estas, reportan participación voluntaria ${ }^{27,34}$, a través de línea de atención inmediata ${ }^{47}$ y referidas por centros de atención a víctimas de violencia de género con diagnóstico previo de trastorno de estrés postraumático -TEPT, ansiedad y depresión 9,29,31,32, con objetivo de disminuir la incidencia y prevalencia de la violencia, reducir los índices de re victimización de sobrevivientes, aumentar denuncia de casos, mejorar bienestar psicológico, modificar prácticas, actitudes y percepciones sobre roles tradicionales de género que normalizan la violencia ${ }^{47}$.

Las intervenciones se enfocan en prevención, sensibilización, tratamiento, rehabilitación y psicoeducación $^{32}$. Los principios más relevantes de las intervenciones son la seguridad de la mujer, la validación de sus experiencias, el énfasis en sus puntos fuertes, la diversificación de sus alternativas, el restaurar la claridad de sus juicios, la compresión de opresión y el empoderamiento para toma de decisiones ${ }^{29}$.

Los estudios con mujeres coinciden en señalar el abordaje multimodal dirigidos a la reestructuración cognitiva frente a la violencia, a través de la exposición en vivo y afrontamiento para la prevención de recaídas, acompañado de psicoeducación en inteligencia emocional ${ }^{9,27,31}$. Estas optan por medidas de pretratamiento, postratamiento y seguimiento, que atenúa síntomas de reexperimentación, evitación y aumenta la activación conductual ${ }^{29,32}$. Se conciben desde una postura "de afuera hacia adentro", presentando los principios de la sociedad patriarcal analizando las características de abuso en relación violenta y las estrategias para huir de ella. Resalta la visión psicoterapéutica de tratamiento que es "desde adentro hacia afuera" que analiza primero la situación de la mujer dentro de la relación de abuso y ésta en el contexto de la sociedad patriarcal en el que ocurre, con el fin de promover habilidades resolutivas y subversivas ${ }^{29}$.

\section{Profesionales que trabajaron con hombres maltratadores}

Los estudios orientados a indagar la experiencia de profesionales y colaboradores que trabajaron con hombres maltratadores conformado por pedagogos, psicólogos, personal de salud y otros ${ }^{28,48}$, contaron con participación voluntaria, indagando las experiencias y percepciones del abordaje de las intervenciones. Éstos identifican la necesidad de incluir la perspectiva de género, acciones coordinadas que mejoren la intervención, la formación permanente del personal, la 
personalización de las intervenciones que se ajuste a los perfiles de los agresores e involucrar a la pareja y su red apoyo; ampliar las modalidades de abordajes (individual, grupal) y número de sesiones, enfatiza en mejorar los recursos humanos y participación interdisciplinar ${ }^{28}$.

\section{Parejas de adultos}

En dos intervenciones con parejas de adultos ${ }^{34,46}$, participaron voluntariamente, con criterios de una convivencia mayor a seis meses presentando niveles de conflicto alto, violencia y querían permanecer en la relación a pesar de las dificultades. El nivel de intervención se orientó al tratamiento en violencia de pareja, sobresaliendo el aprendizaje sobre el reconocimiento de las señales de ira, la detención de las interacciones negativa durante los conflictos y aumento de comunicación asertiva. Resalta el proceso de tratamiento como estrategia satisfactoria que promueve la prevención de recaídas y compromiso al cambio en pareja ${ }^{46}$.

\section{Modalidades de intervención}

Existen distintas modalidades de trabajo: individuales, grupales, abordaje en pareja y combinadas que han sido descritas de mayor aceptabilidad durante las intervenciones. Sin embargo, en pareja están recomendadas únicamente en algunos casos concretos, según las características de los sujetos y deben estar dirigidas especialmente a agresores de bajo riesgo, que presentan alta motivación por el tratamiento y sin abuso de sustancias ${ }^{44}$.

Las intervenciones individuales han recibido menor atención, por el costo y las dificultades de aplicarlas en diferentes contextos, siendo necesario analizar la relación costo beneficio, pues si bien la atención focalizada puede ser necesaria en un momento de la intervención,

La perspectiva de género abarca de forma estructural y epistemológica el abordaje de la violencia y las perspectivas patriarcales a través de un compromiso y practicas subversivas para transformar las perspectivas tradicionales. también se resalta la terapia grupal, como una continuidad al abordaje ${ }^{44}$. La intervención individual logra la atención en crisis en un momento inicial y luego de evaluar la situación, se puede reestructurar el siguiente nivel de intervención desde un abordaje grupal.

El abordaje grupal se identificó como el más eficaz que brinda desde el ámbito pedagógico, social y psicológico, estrategias relacionales y de impacto para trabajar y reelaborar situaciones traumáticas desde un modelo terapéutico basado en establecer vínculos con otras personas que han pasado por una situación similar, en el que resulta significativo y útil para la reconstrucción de vínculos ${ }^{9}$. Igualmente, este tipo de intervenciones en la modalidad combinada, intervenciones grupales de parejas, expone de forma precisa el empoderamiento de la mujer y la participación de su pareja como un hallazgo que fortalece las relaciones desde una perspectiva de género, nuevas masculinidades y expresa una reducción de la violencia, convirtiéndose como una experiencia satisfactoria ${ }^{34,41}$.

Las intervenciones grupales desde un enfoque multimodal (cognitivo conductual, psicología positiva y narrativas), incrementa la percepción de seguridad y de control de los participantes y atenúa el impacto psicológico de la violencia ${ }^{32}$. Técnicas como grupos focales se tenían en cuenta para este abordaje que construye un diagnostico situacional de la violencia de pareja y sus factores asociados, contando con previa capacitación del equipo de trabajo ${ }^{48}$.

Las intervenciones grupales en agresores, incrementan la probabilidad de que identifique sus pensamientos y conductas problemáticas a través de otros miembros del grupo ${ }^{44}$. En mujeres, 
permitía re significar situaciones traumáticas a través de experiencias conjuntas y construir redes de apoyo ${ }^{29}$. Por último, las intervenciones grupales en adolescentes y jóvenes, proponen el incremento de las interacciones y sentido de pertenencia, aumentan la participación, y confianza en este tipo de programas ${ }^{45}$.

\section{Perspectivas y enfoques desde donde se aborda la violencia de pareja}

La violencia y las relaciones de poder en la pareja describen su distribución histórica en las relaciones de género, en relación con el surgimiento de estereotipos de género, y ejercicio de violencia ${ }^{45}$. Las perspectivas que explican la violencia, presentan principales modelos teóricos que exponen la interacción de factores individuales, familiares, sociales y culturales asociados al surgimiento y la perpetuación de la violencia de pareja ${ }^{45}$. (Ver cuadro 2).

El modelo tradicional sexista, el modelo piramidal y la perspectiva clínica de agresores, dan un panorama explicativo de la violencia desde una normatividad hegemónica de las masculinidades y la violencia, estructurado en etapas el sustrato patriarcal, los procesos de socialización sexista, las expectativas de control sobre la mujer, los eventos desencadenantes que genera el estallido de la violencia contra las mujeres en sus diferentes manifestaciones ${ }^{41,44,50}$. Además, el modelo ecológico y la teoría del aprendizaje social, permite entender la violencia a través de diferentes interacciones de múltiples factores que inciden en la historia individual de la víctima o agresor $^{33,36}$. La perspectiva de género abarca de forma estructural y epistemológica el abordaje de la violencia y las perspectivas patriarcales a través de un compromiso y practicas subversivas para transformar las perspectivas tradicionales ${ }^{46}$.

\section{Cuadro 2. Perspectiva, Enfoque, Temáticas e Instrumentos en intervenciones violencia de pareja 2010-} 2019

\begin{tabular}{lll}
\hline No.* & \multicolumn{1}{c}{ Temáticas o componentes } & Instrumentos o estrategias \\
\hline 1 & Perspectiva: Perspectiva de género & \\
Enfoque: NR* & \\
$\begin{array}{ll}\text { 1) Evaluar programas de prevención de violencia } & \text { Resaltan estrategias de los estudios: } \\
\text { 2) Identificar comportamientos violentos y sus repercusiones } & \text { 1) Actividades curriculares y } \\
\text { en la salud como hallazgos para apuntar a la prevención } & \text { comunitarias (obras de teatro, } \\
\text { del fenómeno } & \text { sesiones curriculares, concursos de } \\
\text { 3) Datos cuantitativos del impacto de la violencia en el noviazgo } & \text { carteles, grupos de apoyo, material } \\
\text { 4) Caracterización de la violencia y relaciones de género } & \text { 2) Conferencias } \\
& \text { 3) Dramatizaciones directas) }\end{array}$ \\
& 4) Folletos educativos
\end{tabular}

2 Perspectiva: NR

Enfoque: Modelo de intervención cognitivo conductual

1) Psicoeducación y Reestructuración cognitiva
2) Exposición gradual a las memoras traumáticas y relajación
3) Técnicas de resolución de conflictos
4) Prevención de las reincidencias

1) Entrevista inicial semiestructurada

2) Inventario de ansiedad de Beck

3) Inventario de depresión de Beck

4) Escala de satisfacción con la vida

5) Entrevista estructurada basada en DSM IV / SCID utilizada para evaluar el TEPT***

6) Inventario de síntomas de estrés de Lipp para adultos 
No.*

3 Perspectiva: Perspectiva de género

Enfoque: Perspectiva de género

Se compone de tres unidades centradas en la violencia, el consumo de sustancias y el comportamiento sexual saludable.

1) Seguridad personal y prevención de lesiones (Relaciones saludables, barreras en relaciones saludables, potenciadores de la violencia, conflicto y resolución de conflictos, violencia en los medios, habilidades de resolución de conflictos, actuaciones en la escuela y la comunidad)

2) Crecimiento y sexualidad saludable (sexualidad saludable, en los medios, responsable, prevención de embarazos, etc., asertividad toma de decisiones)

3) Uso y abuso de sustancias (mitos, realidades, definiciones, efectos, toma de decisión, factores)

4 Perspectiva: Perspectiva tradicional sexista

Enfoque: NR

1) Bases teóricas de la violencia (Conceptualización y tipos de violencia en la pareja, La violencia y las relaciones de poder en la pareja, Modelos explicativos de la violencia, Características de la violencia de pareja en jóvenes, Recursos y estrategias para abordar la violencia).

2) Relaciones de pareja saludables: La importancia de la comunicación (Definiendo relaciones de pareja saludable, Comprendiendo las bases de la comunicación, Técnicas de comunicación asertiva)

3) Autoconocimiento y expresión emocional (Conociéndonos, Identificación y expresión de sentimientos, Reconocimiento y manejo de la ira)

4) Resolviendo los conflictos de forma no violenta (Bases teóricas del conflicto y estrategias de resolución, Habilidades de resolución no violenta de conflictos)

5) Integración está compuesto de una sesión, Compartiendo mis aprendizajes

5 Perspectiva: Modelo biológico, sociológico, eco sistémico y evolutivo Enfoque: Modelo pedagógico constructivista Modelo triangular de Sternberg.

1) Honrando el problema

2) Definiendo el milagro

3) Introducción a la violencia de pareja

4) Conciencia plena y plan de seguridad

5) Escalada y tiempo de descanso negociado

6) Uso de drogas y alcohol

7) Sesiones conjuntas basadas en Terapia Breve Centrada en Soluciones para trabajar en asuntos específicos

Cuestionarios

1) Inventario de Relaciones Conflictivas en el Noviazgo Adolescente

2) Encuesta Nacional Longitudinal a Niños y Jóvenes
Cuestionarios

1) Cuestionario de Conocimientos

2) Escala de actitudes

3) Evaluación de seguimiento

4) Entrevistas focalizadas

5) Sesiones organizadas en modalidad de taller
Cuestionarios
1) Lista de chequeo de comporta- mientos de control
2) Escala de Miedo a la Pareja
3) Cuestionario de chequeo de la relación
3) Índice de calidad de la relación
4) Cuestionario de detección de abuso de drogas
5) Cuestionario de identificación de trastornos relacionados con el consumo de alcohol
6) Escala de Depresión del Center for Epidemiologic Studies

6 Perspectiva: Perspectiva de género Enfoque: NR

1) El manejo de conflictos y habilidades para resolver problemas

2) Búsqueda de ayuda

3) Conocimientos sobre relaciones saludables, acoso sexual y asalto sexual

4) Cambio de actitudes sobre la violencia en las relaciones de noviazgo

5) Aumento de conductas apropiadas para prevenir el asalto sexual

6) Control por parte de la pareja

7) Estrategias para terminar una relación de noviazgo con características de malos tratos

8) Mejoramiento de la autoestima para prevenir la violencia en el noviazgo

Estrategias:

1) Obras de teatro

2) Concursos con carteleras

3) Análisis de películas

4) Debates

5) Juego de roles

6) Escritura creativa

7) Cartas dirigidas a una víctima o victimario ficticio 
No**

7 Perspectiva: NR

Enfoque: Modelo cognitivo conductual

1) Psicoeducación al consultante acerca de la problemática de los celos patológicos

2) Selección de conductas problema y registro.

3) Instruir sobre los elementos constituyentes de la terapia cognoscitiva

4) Reconocer las distorsiones cognoscitivas y las creencias irracionales que está presentando el consultante

5) Estrategia de relajación.

6) Modificar creencias y distorsiones cognitivas que promuevan actos de agresión hacia la pareja

7) Contrato conductual para disminuir conductas Inadecuadas relacionadas con la problemática de celos

8) Involucrar a la pareja del consultante en el proceso de intervención terapéutica

8) Acordar con ambos miembros de la pareja la puesta en marcha de la exposición con prevención de respuesta.

9) Promover el renovar actividades placenteras entre los miembros de la pareja

10) Psicoeducación en manejo de recaída en cuanto a su problema de celos

11) Recomendaciones claves para continuar con una relación de pareja saludable.

12) Evaluar mediante test psicológicos el grado de disminución de los celos patológicos

8 Perspectiva: Modelo ecológico

Enfoque: Modelo ecológico

\section{PREVENCIÓN}

1) Disminuir la incidencia y prevalencia de la violencia contra la mujer

2) Reducir los índices de revictimización de mujeres sobrevivientes de la violencia contra la mujer

\section{ATENCION OPORTUNA}

3) Aumentar las denuncias de casos de VCM, REHABILITACION

4) Mejorar el bienestar psicológico de las afectadas; $y$ PROMOCION

5) Modificar prácticas, actitudes y percepciones sobre los roles tradicionales de género en la sociedad que normalizan la violencia contra la mujer.
1) Psicoeducación

2) Autocontrol

3) Reestructuración cognitiva

4) Regulación emocional

5) Terapia en pareja

6) Exposición con prevención de respuesta

7) Prevención de recaídas
1) Entrevista a profundidad

2) Líneas de atención

9 Perspectiva: NR

Enfoque: Modelo transteórico

1) Normas sociales de género

2) Desigualdades

3) Las inequidades de género en los hogares

4) Importancia de la no violencia en el hogar,

5) El respeto y la comunicación entre hombres y mujeres,

6) El reconocimiento de las importantes contribuciones que las mujeres hacen al bienestar del hogar.

7) Empoderamiento económico
1) Cuestionario de elaboración propia de los investigadores de la Escuela de Salud y Medicina Tropical de Londres

10 Perspectiva: NR

Enfoque: Modelo de abordaje

1) Percepción de violencia familiar

2) Calidad de atención del servicio de salud en casos de violencia intrafamiliar

1) Socio drama

2) Grupo focales

3) Organización funcional del servicio de salud para abordar casos de Violencia Intrafamiliar 


\begin{tabular}{|c|c|c|}
\hline No.* & Temáticas o componentes & Instrumentos o estrategias \\
\hline 11 & $\begin{array}{l}\text { Perspectiva: Perspectiva clínica tipológica a agresores } \\
\text { Enfoque: Perspectiva clínica tipológica a agresores }\end{array}$ & \\
\hline & $\begin{array}{l}\text { 1) Motivación (aspectos motivacionales y empatía) } \\
\text { 2) Intervención Síntomas Psicopatológicos (Ira descontrolada, Ideas } \\
\text { distorsionadas sobre los roles sexuales y sobre la violencia como } \\
\text { forma de solución de problemas, ansiedad y estrés) } \\
\text { 3) Intervención en déficits de asertividad y comunicación, déficits en la } \\
\text { resolución de problemas y déficits en las relaciones sexuales } \\
\text { 4) Prevención de recaídas (identificación de situaciones de riesgo y } \\
\text { estrategias adecuadas de afrontamiento). }\end{array}$ & $\begin{array}{l}\text { 1) Entrevista estructurada } \\
\text { 2) Inventario de pensamientos } \\
\text { distorsionados } \\
\text { 3) Escala de autoestima de } \\
\text { Rosenberg } \\
\text { 4) Inventario Clínico Multiaxial de } \\
\text { Millon-III } \\
\text { 5) Inventario de Expresión de Ira } \\
\text { Estado-Rasgo (STAXI-2) } \\
\text { 7) Escala de Impulsividad de Barratt } \\
\text { 8) Conflict Tactics Scales-2 (CTS-2) } \\
\text { 9) Cuestionario de Apego Adulto } \\
\text { 10) Índice de Reactividad } \\
\text { Interpersonal }\end{array}$ \\
\hline
\end{tabular}

12 Perspectiva: Perspectiva de género

Enfoque: Modelo DULUTH (Domestic Abuse Intervention Project)

Estructurado en 10 unidades temáticas

1) Presentación del grupo, objetivos del programa y compromisos.

2) Minimización, negación y culpabilización.

3) Privilegios masculinos.

4) Coacciones y amenazas.

5) Intimidación.

6) Abuso emocional.

7) Abuso sexual.

8) Aislamiento.

9) Abuso económico.

10) Manipulación de los hijos.
1) Conflict Tactics Scale (CTS2)

2) Cuestionario de deseabilidad Social

3) Escala de Ajuste Diádico (DAS)

4) Cuestionario sobre Sexismo Ambivalente (ASI)

5) Inventario de creencias acerca del maltrato a la mujer (IBWB)

6) La versión española de la Spouse Specific Dependency Scale (SSDS)

13 Perspectiva: Perspectiva ecológica Enfoque: Modelo ecológico

El programa está estructurado en 3 fases: Evaluación, Intervención y Seguimiento

1) Toma de contacto. Para el conocimiento del grupo y normas de relación con presentación y experiencias

2) Violencia contra la mujer en las relaciones íntimas: Concepto, tipos y ciclo de la violencia: Conceptos, mitos, tipos, ciclos, hechos. Asunción de responsabilidad y mecanismos de defensa: culpabilidad y hechos

3) Estrategias de cambio, variables personales: Autoconcepto, Autoestima, Emociones y Estrategias de autocontrol

4) Estrategias de cambio: variables interpersonales: Pareja - Hijos

5) Estrategias de cambio: Variables situacionales: Redes sociales y contexto social.

6) Estrategias de cambio: variables socioculturales: Roles, estereotipos y desigualdades de género

7) Fin de la intervención y prevención de recaídas: Cierre

14 Perspectiva: NR

Enfoque: Enfoque motivacional

1) Presentación y motivación para el cambio

2) Identificación y expresión de emociones (Expresión y control de la ira, impulsividad y agresividad)

3) Distorsiones cognitivas y creencias irracionales (Celos patológicos)

4) Asunción de responsabilidad y mecanismos de defensa (Atribución y minimización de responsabilidad)

5) Empatía con la víctima (Empatía)

6) Violencia Física y control de la ira Conflictos de pareja y violencia física (Actitudes sexistas Calidad en la relación de pareja)

7) Agresión o coerción sexual Agresión y coerción sexual en la pareja)

8) Violencia psicológica (Abuso emocional)

9) Abuso e instrumentalización de los hijos

10) Género y violencia de género (Actitudes sexistas)

11) Prevención de recaídas (Calidad en la relación de pareja)

1) Cuestionarios

2) Test estandarizados

2) Entrevista a profundidad

3) Entrevista motivacional

4) Rueda de experiencias

5) Grupos focales
Variables de maltrato

1) Escala de tácticas para la resoluciónde conflictos.

2) Multidimensional Measure of Emotional Abuse.

3) Inventario sobre Sexismo Ambivalente.

4) Escala de Atribución de responsabilidad y Minimización.

5) Quality Marriage Index.

6) Cuestionario de Celos Románticos.

Variables psicológicas específicas

1) Inventario de Manifestación de la Ira Rasgo-Estado

2) Cuestionario de personalidad $I 7$

3) Cuestionario de personalidad $\mathrm{NEO}-\mathrm{FFI}-\mathrm{R}$

4) Cuestionario de Agresión Variables de control

1) Escala de Deseabilidad Social 
15 Perspectiva: Perspectiva de género Enfoque: Enfoque socio afectivo

1) El uso de los iguales como recurso y contexto educativo

2) El desarrollo de las competencias emocionales en los jóvenes como recursos intrapersonales fundamentales para el desarrollo y establecimiento de relaciones sociales sanas

3) La aproximación a la violencia en la pareja adolescente desde el análisis del cortejo, el inicio, consolidación y la experiencia de ruptura de las relaciones de pareja en la adolescencia.

\section{TEMATICAS}

1) "Salir con alguien"

2) "Consolidación" 3) "Ruptura"
1) Cuestionario sobre la violencia en las relaciones de pareja (adaptación de la escala de Crick y la escala CTS2 - Conflict Tactics Scale -

2) Calidad de las relaciones sentimentales (Network Relationship Inventory)

16 Perspectiva: Perspectiva de género Enfoque: Enfoque de género

1) Visibilización e identificación a partir del relato de las mujeres de los distintos tipos de maltrato a los que están o han estado sometidas

2) Expresión de sentimientos, afectos y síntomas relacionados con la experiencia abusiva

3) Integración de la experiencia traumática en la identidad

4) Intervenciones psicoeducativas (situaciones de riesgo, ciclo de la violencia, la indefensión aprendida, el síndrome postraumático, indicadores de violencia, victimización secundaria, amor romántico, estrategias del hombre violento, mitos, creencias sobre víctimas, maltratadores y su proceso.

5) Reconexión con vida social
1) Estrategia psicodramáticas (soliloquis, doblajes, espejo, esculturas e inversión de roles)

2) Reconstrucciones narrativas

17 Perspectiva: Perspectiva de género Enfoque: Enfoque de género

Consta de 6 componentes:

1) Fase psicoeducativa en género y en violencia de género. En esta fase se pretende aumentar la seguridad de las mujeres, la toma de conciencia y la comprensión del proceso de violencia de género vivido. Para ello se trabaja a través de la metodología inductiva.

2) Reducción y/o eliminación de síntomas, para lo cual se utilizan distintas estrategias y técnicas terapéuticas, tales como reestructuración cognitiva, parada de pensamiento, técnicas de manejo del estrés y entrenamiento en relajación.

3) Estrategias y técnicas para aumentar su autoestima y autoeficacia.

4) Fomentar una comunicación y habilidades sociales adecuadas.

5) Aprender y/o mejorar la forma de solucionar los problemas y de tomar decisiones, lo cual se realiza a través de psicoeducación y entrenamiento en solución de problemas y toma de decisiones.

6) Reestructuración cognitiva sobre el amor romántico y la prevención de recaídas.
1) Inventario de evaluación del maltrato a la mujer por su pareja

2) Escala de gravedad de síntomas del trastorno de estrés postraumático

3) Inventario de depresión de Beck-II

4) Inventario de ansiedad de Beck

5) Inventario de autoestima (SEQ-MR)

6) Inventario de apoyo social

18 Perspectiva: Modelo de la teoría del aprendizaje social

Enfoque: Modelo de la teoría del aprendizaje social

El programa LMA consta de ocho sesiones

1) El amor y el enamoramiento

2) Autoconocimiento

3) La intuición

4) El abuso psicológico y el acoso

5) El abuso físico y sexual

6) Los agresores de mujeres

7) ¿Cómo se sale de una relación violenta?

8) Procesos emocionales y psicológicos
1) Cuestionario de evaluación de conocimientos del LMA

2) Cuestionario de información sobre relaciones de pareja en adolescentes

3) Cuestionario de opiniones del alumnado

4) Escala de habilidades sociales (EHS)

5) Cuestionario de actitudes $y$ estrategias cognitivas y sociales (AECS). 
19 Perspectiva: NR

Enfoque: Modelo cognitivo conductual

El programa Contexto está compuesto por 7 módulos

1) Toma de contacto.

2) Violencia de Pareja: Principios Básicos.

3) Estrategias de cambio: Variables Personales.

4) Estrategias de cambio: Variables Familiares.

5) Estrategias de cambio: Variables Situacionales.

6) Estrategias de cambio: Variables Socio-Culturales.

7) Fin de la Intervención: Prevención de Recaídas.
1) Datos sociodemográficos

2) Escala de Percepción de Gravedad de la Violencia contra la Pareja

3) Culpabilización de la víctima (escala tipo Likert)

4) Aceptabilidad de la violencia (escala tipo Likert)

5) Inventario de Sexismo Ambivalente (escala tipo Likert)

6) Intimate Partner Violence Responsibility Attibution Scale

7) Spousal Assault Risk Assessment Guide

20 Perspectiva: Perspectiva de género

Enfoque: Enfoque de género

1) Psicoeducación en género y en violencia de género.

2) Estrategias y técnicas terapéuticas cuyo fin es reducir y/o eliminar sus síntomas

3) Estrategias y técnicas para aumentar su autoestima y seguridad en sí mismas tales como fomento de un autoconcepto adecuado, autorefuerzo y autocuidado y programación de actividades.

4) Fomentar una comunicación y habilidades sociales adecuadas.

5) Entrenamiento en solución de problemas. Además se incluye psicoeducación para fomentar la independencia emocional y técnicas de prevención de recaídas.
1) Entrevista semiestructurada de historia y tipo de maltrato

2) Escala de gravedad de síntomas del trastorno de estrés postraumático

3) Inventario para la ansiedad de Beck

4) Inventario para la depresión de Beck - segunda edición

5) Inventario de autoestima (SEQ-MR Self Esteem Inventory)

6) Inventario de apoyo social

7) Inventario de evaluación del maltrato a la mujer por su pareja

21 Perspectiva: NR

Enfoque: Enfoque de género

1) Sugerencias de mejora del programa.

2) Identificación de las limitaciones.

3) Aplicabilidad a otros delitos de carácter ideológico.

4) Identificación de indicadores de éxito de la intervención con maltratadores.

5) Identificación de perfiles de maltratadores en relación a la intervención.

6) Identificación de posibles cambios de perfil en la nueva pareja.

7) Niveles de reincidencia. -Identificación de resistencias al programa por parte de los maltratadores.

22 Perspectiva: Modelo piramidal

Enfoque: Nuevas masculinidades

Componentes de las revisiones:

1) Programas llevados a cabo en los centros penitenciarios y sus secciones abiertas

2) Programas como medida penal alternativa

3) Programas de asistencia voluntaria, que trabajan con varones que acuden voluntariamente y se desarrollan en contextos comunitarios (por ejemplo, ayuntamientos, colegios profesionales, centros terapéuticos, asociaciones y organismos autonómicos)

4) Analizar si la intervención incluye un componente cognitivo para desmontar o desactivar el modelo mental sexista sobre la violencia de género (reconstruir las ideas sexistas, las distorsiones y sesgos cognitivos sobre la violencia, sobre el sexismo, sobre el rol masculino y sobre la identidad masculina tradicional)

5) Analizar si la intervención incluye un componente emocional para modificar las asociaciones emocionales con la conducta violenta (trabajar emociones de ira, frustración, impotencia, celos, miedo, ligadas a la identidad masculina tradicional y la violencia).
Resaltan las estrategias de los siguiente programas:

1) Programa de asistencia voluntaria del Servei d'Atenció a Homes que Maltratan (SAHM) de la Fundación IRES

2) Programa Psicosocial para Agresores en el Ámbito de la Violencia de género de la Universidad de Granada 
23 Perspectiva: Perspectiva de género

Enfoque: Modelo comunitario y enfoque cognitivo conductual

Los estudios presentan los siguientes componentes:

1) Los problemas de salud mental

2) El abuso de sustancias

3) La cultura y la historia de traumas del perpetrador en el patrón de abuso

4) Tratamiento requerido

5) Historia de victimización de los hombres que abusan físicamente de sus parejas y su conexión con la conducta abusiva como adultos

6) La conexión entre la raza o etnicidad, la clase social, el contexto vital, la masculinidad y la violencia doméstica

7) La liga entre problemas de salud mental y de desarrollo y la violencia doméstica

8) La conexión entre las experiencias de los hombres con la paternidad y su conducta violenta como adultos
Resalta estrategias de los estudios:

1) Terapia cognitivo conductual

2) Conflict Tactic Scale CTS

3) Rehabilitación basada en la comunidad

4) Inventory of Beliefs about Wife Beating

5) Sympathy for Battere Women Scale

6) The Novaco Anger Scale

7) The personal Dependency Inventory

8) The Multidimensional Locus of Control Scale

9) The Abusive Behavior Inventory

10) The Balanced Investory of Desired Responding

11) Entrevistas individuales

12) Cuestionario abierto sobre satisfacción del tratamiento

24 Perspectiva: NR

Enfoque: Modelo ecológico y teoría del cambio

1) Inicio (Aprender sobre la comunidad Selección de activistas comunitarios fomentando el poder con el personal y los activistas comunitarios),

2) Conciencia (Ayudar a los activistas a ganar confianza, Actividades informales Fomentar el pensamiento crítico sobre el "poder sobre" de las mujeres de los hombres),

3) Apoyo (Fortalecer las habilidades y las conexiones entre los miembros de la comunidad Unirse a "poder con" a otros para apoyar el cambio)

4) Acción (Probar nuevos comportamientos celebrando el cambio Fomentar el "poder a" hacer un cambio positivo)
1) Activismo local

2) Medios de comunicación y promoción

3) Materiales de comunicación y capacitación

4) Actividades de intervención

*Los números de las investigaciones corresponden a los nombres asignados en el cuadro anterior (Ver Cuadro 1)

**NR: No reporta.

*** TEPT: Trastorno de Estrés Post Traumático.

Los enfoques de las intervenciones de violencia de pareja se abordaron desde un modelo cognitivo conductual ${ }^{9,27,40}$, motivacional ${ }^{37}$, socio afectivo ${ }^{36}$ y de abordaje ${ }^{48}$, que evidencian efectos positivos en la proceso de cambio, hace énfasis en análisis funcional, reestructuración de vínculos, aceptación y compromiso al tratamiento ${ }^{27}$. El enfoque pedagógico constructivista ${ }^{45}$, resalta el aprendizaje como un proceso que tiene una función adaptativa, promueve la experimentación y resolución de problemas y considera que los errores son la base del aprendizaje ${ }^{50}$.

El enfoque de género $29,31,32,49$, el modelo de Duluth ${ }^{43}$ y ecológico $30,33,42,47$, es recomendado en la intervención con todos los sujetos abordados, y destacan niveles de análisis (personales, interpersonales, contextuales y sociales), los factores de riesgo y protectores para su intervención, presentando efectividad ${ }^{42}$. El modelo de la teoría del cambio $^{35}$, el modelo transteórico ${ }^{34}$, el modelo comunitario ${ }^{40}$ y el modelo de las nuevas masculinidades ${ }^{41}$, son una propuesta que surge del trabajo con maltratadores y adopta a profundidad la noción de masculinidad tradicional, aceptando renunciar a los privilegios de la sociedad patriarcal, que daría lugar a cambios de mayor profundidad y duraderos ${ }^{41}$. 


\section{Dimensiones de las intervenciones}

Las dimensiones que se abarcan en las intervenciones de violencia de género en relaciones de pareja, está integrado por perspectiva, enfoque, temáticas y componentes e instrumentos que se describen según los sujetos abordados, finalmente los profesionales y expertos. (Ver cuadro 2)

El principal objetivo de las intervenciones realizadas con adolescentes, estaban relacionados con prevención de conductas de violencia en la pareja, tanto para hombres como mujeres, en una edad más temprana, por lo cual las intervenciones se enfocaron en bases teóricas y de intervención ${ }^{38}$. Las bases teóricas fueron: el amor y el enamoramiento, tipos de violencia, modelos explicativos de la violencia, reconocimiento y sensibilización frente a la violencia, estereotipos de género, relaciones saludables, resolución de conflictos, sexualidad saludable y responsable, abuso de sustancias, conductas que indican violencia de pareja, experiencias de ruptura de relaciones de pareja, salida de una relación violenta ${ }^{36,49}$. Las bases de intervención fueron: Autoconocimiento, expresión emocional, resolución de conflictos, cambio de actitudes sobre la violencia en las relaciones de noviazgo, mejoramiento de la autoestima, relaciones sociales sanas y saludables, procesos emocionales y psicológicos para evitar violencia ${ }^{49}$.

Los instrumentos utilizados para estas mediciones, constaron básicamente de cuestionarios sobre conocimientos, actitudes y opiniones: Inventario de Relaciones Conflictivas en el Noviazgo Adolescente Cuestionario de información sobre relaciones de pareja en adolescentes, Encuesta Nacional Longitudinal a Niños y Jóvenes, Escala de habilidades sociales (EHS), entrevistas (focalizadas, semiestructurada individual) ${ }^{38}$.

En la población de hombres maltratadores, las intervenciones se basan principalmente en tres fases ${ }^{44}$. La primera es relacionada con educación y motivación inicial que tiende a demostrar las responsabilidades y el reconocimiento de la empatía, presentación del grupo, objetivos del programa, normas de relación, motivación para el cambio, y generalidades sobre la violencia y la salud mental ${ }^{43}$.

La segunda parte es la intervención en sí, con la que se logra cambio en las actitudes, comportamientos y creencias, basados en información sobre ciclo de la violencia, distorsiones cognitivas (celos patológicos, minimización de la responsabilidad), control emocional (impulsividad, agresividad), celos, asertividad, resolución de problemas, tipos de abuso (emocional, sexual, asilamiento, económico, manipulación de los hijos e instrumentalización), conceptos, mitos, tipos, ciclos, hechos, estrategias de cambio (variables personales, variables interpersonales, variables situacionales y socioculturales), estereotipos y desigualdades de género, problemas de salud mental y su evolución (abuso de sustancias, historial de trauma, victimización, relación en pareja y como padres $)^{40,41}$.

La tercera parte se conoce como cierre, evaluación y seguimiento de la intervención, que se concentra en la identificación de riesgos y estrategias de afrontamiento que prevengan las recaídas, entendiendo estas como la no reincidencia de la conducta de violencia de cualquier tipo, no presencia de denuncias por la misma causa, mejoramiento de la calidad de la relación de pareja ${ }^{37}$.

Enfocados en estas temáticas, los instrumentos de medición basados en identificación de cualidades de personalidad de acuerdo a manuales diagnósticos, instrumentos específicos sobre violencia y cuestionarios generales consecuentes con la problemática: Los inventarios de perso- 
nalidad utilizados fueron: Inventario de pensamientos distorsionados, Escala de autoestima de Rosenberg, Cuestionario de personalidad NEO-FFI-R, Inventario Clínico Multiaxial de Millon-III, Inventario de Expresión de Ira Estado-Rasgo (STAXI-2), Escala de Impulsividad de Barratt, ConflictTactics Scales-2 (CTS-2), Cuestionario de Apego Adulto, La versión española de la Spouse Specific Dependency Scale (SSDS), Escala de Ajuste Diádico (DAS), Cuestionario sobre Sexismo Ambivalente (ASI). Los instrumentos específicos como el Inventario de creencias acerca del maltrato a la mujer (IBWB), Multidimensional Measure of Emotional Abuse, Cuestionario de Celos Románticos, Escala de Percepción de Gravedad de la Violencia contra la Pareja, Culpabilización de la víctima, Aceptabilidad de la violencia. Otras escalas generalizadas, como la Escala de tácticas para la resolución de conflictos, Inventario sobre Sexismo Ambivalente, Escala de Atribución de responsabilidad y Minimización, Cuestionario de Agresión, Escala de Deseabilidad Social $30,37,42,44$.

Las intervenciones realizadas con mujeres, tienen un enfoque diferente, y las temáticas se basan en tres pilares fundamentales. La primera se basa en psicoeducación sobre las problemáticas, el reconocimiento de las mismas (celos patológicos, tipos de violencia, experiencias traumáticas, expresión de sentimientos, afectos y síntomas relacionados con la experiencia abusiva) ${ }^{27}$.

La segunda se basa en la intervención como tal en donde se utilizan estrategias psicológicas de reestructuración cognitiva en cuanto al reconocimiento de distorsiones cognitivas y creencias irracionales que promueven las conductas agresivas de la pareja, recuperación de las relaciones de pareja de forma saludable, realización de actividades placenteras, promoción del respeto y la comunicación en la pareja, reconocimiento de las importantes contribuciones que las mujeres hacen al bienestar del hogar, estrategias y técnicas para aumentar la autoestima y seguridad, fomento de un autoconcepto adecuado, autorefuerzo y autocuidado, comunicación y habilidades sociales adecuadas ${ }^{9,47}$.

La tercera parte se basa en evitar las recaídas, que están definidas por las siguientes conductas: no presencia de nuevos episodios de violencia, disminución de celos patológicos, mejoramiento del bienestar psicológico, empoderamiento económico, reconexión con la vida social e independencia emocional $\mathbf{l}^{9,27,29,34,47}$.

Los instrumentos utilizados para estas intervenciones se centraron en identificación de síntomas: Inventario de ansiedad de Beck, Inventario de depresión de Beck, Escala de satisfacción con la vida, Inventario de síntomas de estrés de Lipp para adultos, Inventario de evaluación del maltrato a la mujer por su pareja, Escala de gravedad de síntomas del trastorno de estrés postraumático, Inventario de autoestima -SEQ-MR, realización de entrevistas (semiestructurada, estructurada para evaluar TEPT, a profundidad, ), realización de cuestionarios propios como el desarrollado por Investigadores de la Escuela de Salud y Medicina Tropical de Londres ${ }^{8,31,32}$.

Los abordajes utilizados para los expertos y profesionales de la salud que durante su experiencia laboral han sido estrategias para prevenir la violencia de pareja, basado en: entrevistas a profundidad sobre las opiniones de los profesionales sobre la calidad de los programas, los indicadores de éxito, las limitaciones, las oportunidades de mejora para los programas, y la identificación de resistencias a los programas, así como la medición de conductas reincidentes. Se centra en la realización de una crítica constructiva, al funcionamiento de los sistemas de salud para brindar atención en los casos de violencia intrafamiliar, sugiriendo acciones de mejora para lograr una organización funcional de los servicios de salud y otros sectores para abordar estos casos presentados. Este abordaje se realizó mediante entrevistas semiestructuradas aplicadas de forma individual y otras sesiones grupales como grupos focales ${ }^{43,48}$. 
El equipo de profesionales que participaron en la formación de las intervenciones de la violencia de pareja, contaba con epidemiólogos, trabajadores sociales, expertos en la realización de técnicas para la evaluación de las intervenciones ${ }^{48}$, docentes en salud y educación, que recibieron taller formativo, dictado por psicólogos y educadores, formados y especializados en el tema ${ }^{33,49}$. Los profesionales de salud contaban con estudios de posgrados en violencia de género y en programas de intervención ${ }^{32}$. En el campo comunitario, participaron policías, líderes institucionales, gubernamentales, culturales, locales, hombres y mujeres interesados en promover estrategias de prevención primaria ${ }^{35}$, y abogados para la activación de ruta de atención según el tipo de violencia ${ }^{47}$.

\section{Seguimiento y evaluación de la efectividad de las intervenciones}

Para implementar intervenciones en violencia de género en relaciones de pareja, desde niveles educativos, preventivos, de tratamiento y rehabilitación, se debe identificar si las diferencias culturales inciden o no en los resultados. Por tal motivo, en el estudio ¿Influyen las diferencias culturales en los resultados de los programas de intervención con maltratadores? Un estudio con agresores españoles y latinoamericanos demostraron que la intervención realizada presentó un incremento en la percepción de gravedad de la violencia contra la pareja y disminución en variables que legitimaban la violencia como la culpabilización a la víctima y el sexismo, reduciendo el porcentaje de la atribución de responsabilidad al sistema legal y a la víctima, así como el riesgo de reincidencia de violencia contra la pareja. Y se concluye que no es necesario realizar adaptaciones culturales en las intervenciones para lograr un cambio en las actitudes y creencias relacionadas con la violencia en las parejas ${ }^{30}$.

Se resalta los aportes y la eficacia de las intervenciones, como son los programas de intervención grupal con mujeres víctimas que utilizan la Guía Protocolizada de Matud, que demuestra cambios significativos en variables clínicas de ansiedad, depresión y Trastorno de Estrés Post-Traumático -TEP, que se mantuvieron hasta el seguimiento de tres y seis meses ${ }^{31}$. Muy similar son los resultados en el tratamiento psicológico individual con la misma guía, en donde las mujeres tras el programa de intervención presentaron un aumento en su autoestima, ganando más confianza en sí mismas y manifestando mayor apoyo social, emocional e instrumental. Además, evidenciaron una menor sintomatología de reexperimentación, evitación y de aumento de la activación ${ }^{32}$.

La violencia de pareja en los adolescentes, se encontró que los tipos de violencia más frecuentes en los noviazgos son: el abuso psicológico que se presenta con humillaciones, insultos y especialmente, manifestaciones de control psicológico y acoso como «intentar saber en todo momento lo que hacía...», «prohibir salir con amistades», «prohibir determinada ropa», «he tenido que estar de acuerdo para evitar problemas» y conductas de abuso físico como empujones ${ }^{32}$, que genera sentimientos de tristeza, desvalorización y minusvalía, afectando su autoestima como consecuencia natural de una situación en la que la mujer se ha sentido durante mucho tiempo descalificada, avergonzada y agredida por parte de su pareja ${ }^{29}$.

Para este tipo de situaciones, programas como el DaViPop resulta útil en el entorno educativo porque utiliza técnica de juego de roles y aborda tres puntos claves en el proceso del noviazgo: el cortejo, la consolidación de la relación y la ruptura o terminación, que reflejan cambios significativos frente a las variables de apoyo social y expectativas frente al futuro ${ }^{36}$. También, el Programa la Cuarta $\mathrm{R}$ se destaca porque reduce la violencia de pareja entre los adolescentes en el tiempo, especialmente en los chicos, debido a que ambos sexos muestran una mayor aceptabilidad del uso de violencia física para las chicas que para los chicos, en el cual las chicas 
describen las circunstancias como, argumentando que es una respuesta a la violencia ejercida inicialmente por sus parejas ${ }^{49}$.

Investigaciones dirigidas a la rehabilitación y educación en hombres judicializados privados de su libertad por violencia de pareja, se destaca El Programa Contexto que está orientado al cambio de conductas y actitudes violentas hacía la mujer evitando su reincidencia con una percepción de los participantes de $75 \%$ de satisfacción y una tasa de abandono del 34\% que se encuentra por debajo de este tipo de programas dirigidos a esta población ${ }^{41}$. Además, el Programa de Tratamiento con Agresores PRIA está guiado hacia el cambio de actitudes sexistas, la atribución de responsabilidad, la impulsividad y adicionalmente, la expresión y control de la ira, así como conductas de abuso emocional ${ }^{37}$.

Entre los estudios realizados con maltratadores en España, se clasifican en tres tipos de programas $^{41}$ :

I) Programas llevados a cabo en los centros penitenciarios especialmente para personas condenadas por delitos relacionados con violencia de género que participan voluntariamente a los cuales se les realiza seguimiento y evaluación.

II) Programas como medida penal alternativa, en el cual están judicializados con una pena menor a dos años, pero no son privados de su libertad y por el contrario ingresan a estos programas como medida alternativa para educarse en el manejo de sus actitudes y comportamientos agresivos, evitando su reincidencia.

III) Programas de asistencia voluntaria, que se llevan a cabo en contextos comunitarios.

Las intervenciones con agresores, debe ser considerado uno de los principales frentes de actuación a la hora de prevenir la violencia contra la pareja, especialmente los sujetos que han sido condenados con el fin de evitar, la reincidencia y el abandono de los tratamientos, teniendo en cuenta que los maltratadores se agrupan de acuerdo a sus características de personalidad en:

1. Compulsivo o rígido: suelen imponer disciplina y exigencias elevadas a los demás, tiene una visión de la realidad desde su punto de vista e intenta que su pareja vea las cosas como él, porque "está convencido que es la mejor manera para ella".

2. Dependiente: tienen dificultad para asumir roles independientes, buscan apoyo afectivo y seguridad, se muestra ansiosamente desamparado ante la posibilidad de perder a la pareja y no concibe la vida separado de ella.

3. Deseabilidad social: gran necesidad de mostrarse con una buena imagen en su entorno social, moralmente virtuoso y emocionalmente ajustado.

Por último, se destacan las intervenciones ligadas al tratamiento de los celos patológicos mediante la terapia cognoscitiva-conductual que logra una mejoría significativa en la conducta violenta, que garantiza el mantenimiento de los resultados implementando técnicas efectivas como: reestructuración cognitiva, técnicas de relajación y autocontrol. Sin embargo, para obtener mejores resultados es importante fortalecer el manejo de la intolerancia a la incertidumbre, las señales de seguridad y el valor informativo de los estímulos ${ }^{27}$.

\section{Discusión}

En Colombia, los intervenciones de prevención de violencia de género que se han venido desarrollando son las "líneas amigas o de escucha" que buscan reducir problemáticas relacionadas con salud mental, especialmente atención y reducción de violencia de género, aportando al 
bienestar psicológico de las mujeres mediante su empoderamiento y la articulación institucional para el actuar oportuno, ofreciendo soluciones y acompañamiento a las mujeres víctimas de violencia mediante la sensibilización al personal de la Policía que recibe las Ilamadas y eliminando temores, prejuicios o estigmas en torno a denunciar a sus agresores ${ }^{47}$.

Sin embargo, en el sector salud, se han detectado deficiencias en la atención, la respuesta oportuna e integral, la falta de apoyo y seguimiento de las mujeres violentadas por sus parejas. Por este motivo, se propone trabajar de forma articulada con funcionarios del sector salud, protección y justicia en las rutas de atención integral en violencia mediante sensibilizaciones, talleres y capacitaciones lúdico-recreativas que fomenten el empoderamiento individual y permita el desarrollo de habilidades colectivas que produzcan cambios en los discursos para evitar la revictimización y una mejor atención a las víctimas ${ }^{48}$.

De igual manera, surge otro modelo de intervención primaria que se podría implementar desde los Planes de Intervenciones Colectivas -PIC, teniendo en cuenta los resultados obtenidos en la zona rural de Costa de Marfil, en el estudio de Normas Sociales de Género y Empoderamiento Económico, el cual presenta una reducción significativa en las actitudes de justificación y aceptación de la violencia de pareja en las mujeres, al igual que el abuso económico ${ }^{34}$. Por esta razón, las actividades para la prevención de la violencia de pareja deben estar direccionadas en el abordaje de las desigualdades de género en los hogares junto con el empoderamiento económico de la mujer, siendo evaluadas mediante cuestionarios pretest y postest, haciendo el respectivo seguimiento y comparando Las actividades para la prevención de la violencia de pareja deben estar direccionadas en el abordaje de las desigualdades de género en los hogares junto con el empoderamiento económico de la mujer. con las cifras de violencia de pareja ${ }^{34}$.

En el modelo preventivo, los programas psicoeducativos desarrollados quedan incompletos debido a que sólo se enfocan en entorno escolar y comunitario, dejando de lado la importancia de la prevención y detección de la violencia en los servicios de salud como el entorno familiar que es la red de apoyo principal para las víctimas de violencia de pareja.

En este sentido, para la prevención de la violencia de pareja es importante la creación de espacios de diálogo y de reflexión donde los involucrados aporten en la construcción de políticas públicas, originadas desde sus necesidades, asociadas a la construcción de la identidad de género, la sexualidad y la determinación de la violencia. Sin embargo, para lograr una mayor participación en los programas de prevención, tratamiento y rehabilitación es necesario que los grupos de intervención sean pequeños, trabajando inicialmente la autoconfianza y seguridad en sí mismas, fomentando la interacción entre ellas en el intercambio de experiencias y disminuyendo el tiempo dedicado a la teoría para centrarse más en el desarrollo de sus propias habilidades y capacidades.

Por lo anterior, es posible y necesario brindar atención en salud a los agresores mediante programas de rehabilitación cuyo objetivo principal es lograr una transformación personal, a través de cambios significativos en su forma de pensar y actuar, cumpliendo las siguientes condiciones:

I) El maltratador debe ser considerado completamente responsable del uso de la violencia y deberá cumplir las consecuencias de la realización de actos abusivos hacia la pareja. 
II) El maltratador debe fomentar un ambiente de respeto, no violento o crítico en el hogar.

III) El maltratador debe estar dispuesto a trabajar en un proceso largo, doloroso y honesto consigo mismo, haciéndose responsable de sus actos.

No debemos olvidar que el fin último es garantizar la máxima seguridad de víctimas, modificar las conductas agresivas de los sujetos y evitar futuras agresiones y nuevas victimizaciones, todo ello mediante las actuaciones más adecuadas ${ }^{44}$.

\section{Conclusiones}

En la revisión de la literatura, se evidenció que la mayoría de las intervenciones frente a la violencia de género en pareja son de tipo preventivo con una metodología direccionada tanto al fortalecimiento de conocimientos y como al desarrollo de habilidades para afrontar la violencia $^{39}$; focalizados en la identificación de los tipos de violencia, el desarrollo de recursos personales como la empatía, la comunicación y la asertividad y en procesos reflexivos que cuestionan valores culturales que perpetúan la violencia ${ }^{45}$.

Los programas de prevención de violencia en el noviazgo contribuyen a reconocer las distintas manifestaciones y dinámicas de la violencia, al igual que las etapas del ciclo de la violencia y las consecuencias tanto a nivel emocional como comportamental e incentivan la reflexión sobre la importancia de establecer relaciones basadas en la protección, el respeto, la confianza y la honestidad ${ }^{33}$.

Los programas psicoeducativos y de rehabilitación enfatizan en visibilizar la violencia y sus efectos. Las intervenciones con maltratadores no pretenden justificar al agresor; y se enfocan en lograr cambios reales y duraderos, diseñados desde un enfoque de género, trabajando temáticas relacionadas con las nuevas masculinidades, para modificar pensamientos, creencias y actitudes machistas generadas y mantenidas a partir de las relaciones de poder desiguales establecidas por una sociedad patriarcal y sobrevaloración de la violencia.

Respecto a la eficacia de las intervenciones analizadas se identifican los siguientes tópicos sobre los que se recomienda ampliar la reflexión y fortalecer procesos de investigación:

1) Los modelos teóricos y explicativos de las causas de la violencia de género en el marco de la relación de pareja deben analizar, tanto de manera independiente como interrelacionada los aspectos vinculados a la esfera privada y la pública.

2) Gestionar una respuesta pertinente y culturalmente ajustada del sistema judicial, frente a las víctimas, así como el compromiso con la rehabilitación de los agresores, aporta a la disminución de la violencia en sus diferentes expresiones y la reincidencia de la misma.

3) Promocionar la salud integral desde los espacios comunitarios brindando herramientas para mejorar la calidad de vida mediante estrategias que aporten a la convivencia y la resolución asertiva de conflictos, aporta a disminuir la legitimidad de la violencia como estrategia culturalmente aceptada.

4) Considerar la salud mental y reconocer la historia de vida de víctimas y victimarios como variables a incorporar y dimensión a abordar en las diferentes estrategias independiente del nivel en el que se desarrolle

5) Orientar las estrategias al trabajo con la pareja, con miras a transitar de acciones punitivas a intervenciones orientadas a la formación de la comunidad y al establecimiento de medidas de control y acompañamiento social 
6) Fomentar el análisis crítico de la práctica investigativa en la materia, a partir de parámetros de la ética en la salud pública.

Los programas para la violencia de pareja son un elemento que surge de la necesidad contextual de dar respuesta a una problemática social como es específicamente la violencia de género en pareja y, por tanto, se convierte en prioridad el evaluar la efectividad de estos programas de intervención, considerando la capacidad de cobertura y de atención. Además, sin perder de vista la eficiencia del sistema de salud, judicial, político y social en un contexto comunitario, que permita generar un impacto.

Finalmente, es indispensable una política pública en el sector educativo, en la cual se incluyan los programas de prevención de la violencia de pareja dentro del Proyecto Educativo Institucional (PEI) como eje transversal, que incluya un entrenamiento previo a todos los docentes para que realicen el trabajo psicoeducativo con los adolescentes y poder reducir el número de casos de violencia de pareja a mediano y largo plazo. De la misma manera, es necesario incluir dentro de la política pública en salud mental, la atención gratuita tanto a víctimas como agresores para acceder a programas de tratamientos y/o rehabilitación, teniendo en cuenta que la violencia está acompañada de conductas, actitudes, pensamientos, creencias que se pueden modificar, generando cambios positivos mediante una intervención apropiada según las características de la población, dirigida por profesionales cualificados que realicen seguimiento trimestral mínimo durante un año, evitando la reincidencia de comportamientos violentos.

Conflicto de intereses: las autoras manifiestan no tener ningún conflicto de intereses.

\section{Referencias}

1. Ministerio de la Mujer y Poblaciones Vulnerables. Violencia basada en género. Marco conceptual para las políticas públicas y la acción del estado [Internet]. [Citado 23 de mayo de 2020]. Disponible en: https://www.mimp.gob.pe/files/direcciones/dgcvg/mimp-marco-conceptual-violencia-basada-en-genero.pdf

2. Oficina del Alto Comisionado de las Naciones Unidas para los Derechos Humanos (ACNUDH). Declaración sobre la eliminación de la violencia contra la mujer [Internet]. [ Citado 23 de mayo de 2020]. Disponible en:

https://www.ohchr.org/sp/professionalinterest/pages/violenceagainstwomen.aspx

3. Oficina del Alto Comisionado de las Naciones Unidas para los Derechos Humanos (ACNUDH) | Violencia contra las mujeres [Internet]. [Citado 19 de agosto de 2019]. Disponible en: https://www.ohchr.org/SP/Issues/Women/WRGS/Pages/VAW.aspx

4. Sánchez LS. Resiliencia en violencia de género. Un nuevo enfoque para los/las profesionales sanitarios/as. Journal of Feminist, Gender and Women Studies. [Internet]. 2015;(1). Disponible en: https://revistas.uam.es/revlUEM/article/view/416

5. Facio A. La Carta Magna de todas las mujeres. Módulo de la CEDAW. 1998;12. [Internet] Disponible en: http://cdhdfbeta.cdhdf.org.mx/wp-content/uploads/2016/09/Carta-magna-de-todas-las-mujeres.pdf

6. Amnistía Internacional. Informe 2017/18 Amnistía Internacional: La Situación de los Derechos Humanos en el Mundo. Londo, Reino Unido.: Amnesty International; 2018. [Internet]. [Citado 19 de agosto de 2019] Disponible en: https://www.amnesty.org/download/Documents/POL1067002018SPANISH.PDF

7. Águila Gutiérrez Y, Hernández Reyes VE, Hernández Castro V. Consecuencias de la violencia de género para la salud y formación de los adolescentes. Situación que enrarece el entorno social y demanda ser prevenida. revmedicaelectronica [Internet]. 2016 [citado 2019 Ago 12];38(5): Disponible en: 
http://www.revmedicaelectronica.sld.cu/index.php/rme/article/view/1867

8. Organización Panamericana de la Salud (OPS). Comprender y abordar la violencia contra las mujeres: Violencia infligida por la pareja. 2013; [Internet]. [citado 19 de agosto de 2019]. Disponible en: https://apps.who.int/iris/bitstream/handle/10665/98816/WHO_RHR_12.36_ spa.pdf?sequence $=1$

9. Chaib F, Orton J, Steels K, Ratsela K. Estimaciones mundiales y regionales de la violencia contra la mujer: prevalencia y efectos de la violencia conyugal y de la violencia sexual no conyugal en la salud. Ginebra: Organización Mundial de la Salud. 2013; [Internet] [citado 19 de agosto de 2019]. Disponible en: https://apps.who.int/iris/handle/10665/85243

10.Organización Mundial de la Salud (OMS). Estudio multipaís de la OMS sobre salud de la mujer y la violencia doméstica: primeros resultados sobre prevalencia, eventos relativos a la salud y respuestas de las mujeres a dicha violencia: resumen del informe. Ginebra: OMS; 2005. [Citado 19 de agosto de 2019]. Disponible en: https://www.who.int/gender/violence/ who_multicountry_study/summary_report/chapter1/es/

11. Lucena KDT de, Vianna RP de T, Nascimento JA do, Campos HFC, Oliveira ECT. Association between domestic violence and women's quality of life. Revista Latino-Americana de Enfermagem [Internet]. 5 de junio de 2017 [citado 1 de agosto de 2019];25(0). https://doi.org/10.1590/1518-8345.1535.2901

12. Calvo González G, Camacho Bejarano R. La violencia de género: evolución, impacto y claves para su abordaje. Enferm. glob. [Internet]. 2014 Ene [citado 2019 Ago 13] ; 13( 33 ): 424-439. https://doi.org/10.6018/eglobal.13.1.181941

13. Habigzang LF, Aimèe Schneider J, Petroli Frizzo R, Pinto Pizarro de Freitas C. Evaluation of the Impact of a Cognitive-Behavioral Intervention for Women in Domestic Violence Situations in Brazil. Universitas Psychologica. 2018;17(3):52-62.

https://doi.org/10.11144/Javeriana.upsy17-3.eicb

14. Programa de las Naciones Unidas para el Desarrollo (PNUD); Objetivos de Desarrollo Sostenible. [Internet]. [citado 19 de agosto de 2019]. Disponible en: https://www.undp.org/ content/undp/es/home/sustainable-development-goals/goal-5-gender-equality.html

15. Instituto Nacional de Medicina Legal y Ciencias Forenses (INMLCF); Boletines Estadísticos Mensuales; Grupo Centro de Referencia Nacional sobre Violencia (GCRNV) [Internet]. [citado 19 de agosto de 2019]. Disponible en:

http://www.medicinalegal.gov.co/cifras-estadisticas/boletines-estadisticos-mensuales

16. Aiquipa Tello JJ. Dependencia emocional en mujeres víctimas de violencia de pareja. REVPSICOLOGIA [Internet]. 30jun.2015 [citado 12ago.2019];33(2):411-37. Disponible:

http://revistas.pucp.edu.pe/index.php/psicologia/article/view/13050

17. Cortés J, Ivethe C, Rivera Aragón S, Amorin de Castro EF, Rivera Rivera L. Violencia de pareja en mujeres: prevalencia y factores asociados. Acta de investigación Psicológica. [Internet]. 2015;5(3):2224-39. https://doi.org/10.1016/S2007-4719(16)30012-6

18. Puente-Martínez A, Ubillos-Landa S, Echeburúa E, Páez-Rovira D. Factores de riesgo asociados a la violencia sufrida por la mujer en la pareja: una revisión de meta-análisis y estudios recientes. Anal. Psicol. [Internet]. 2016 Ene [citado 2019 Ago 13] ; 32( 1 ): 295-306. https://doi.org/10.6018/analesps.32.1.189161

19. Valdez-Santiago R, Híjar-Medina MC, Salgado de Snyder VN, Rivera-Rivera L, Avila-Burgos L, Rojas R. Escala de violencia e índice de severidad: una propuesta metodológica para medir la violencia de pareja en mujeres mexicanas. Salud pública Méx [revista en la Internet]. 2006 Ene [citado 2019 Ago 12] ; 48( Suppl 2 ): s221-s231.

https://doi.org/10.1590/S0036-36342006000800002

20. Gallardo R, Concha-Salgado A. Propiedades psicométricas del Manual para la Valoración del Riesgo de Violencia contra la Pareja (SARA) en agresores chilenos. Terapia psicológica. 2017;35(2):127-40. https://doi.org/10.4067/s0718-48082017000200127

21. Pueyo AA, López S, Álvarez E. Valoración del riesgo de violencia contra la pareja por medio 
de la SARA. Papeles del psicólogo. [Internet]. 2008;29(1):107-22 Disponible en:

https://www.redalyc.org/articulo.oa?id=77829112

22. Guzmán MO, Tani F, Riverón GEB, Bonechi A, Menna P. Guzmán MO. Cuestionario Maltrato en el Noviazgo (CMN): Instrumento Binacional (Italia-México). 2015; Revista de Psicología Journal of Psychollogy. [Internet]. 2015;14:47-60. Disponible en:

http://revistas.ucv.edu.pe/index.php/R_PSI/article/view/181

23. Hinojosa L, Enrique D. Prevención y Sensibilización de Violencia de Género en Jóvenes Universitarios. Tesis. 2017 [citado 20 de agosto de 2019]; Disponible en:

http://repositorio.ug.edu.ec/handle/redug/25228

24. Pazos Gómez M, Delgado O, Hernando ÁH. Violencia en relaciones de pareja de jóvenes y adolescentes. Revista latinoamericana de psicología. [Internet]. 2014;46(3):148-59. Recuperado de: https://www.redalyc.org/articulo.oa?id=80533065002

25. Cantera LM, Blanch JM. Percepción Social de la Violencia en la Pareja desde los Estereotipos de Género. Psychosocial Intervention. [Internet]. 2010;19(2):121-7. Disponible en: http:// scielo.isciii.es/scielo.php?script=sci_arttext\&pid=S1132-05592010000200003\&lng=es.

26. Naciones Unidas división para el Adelanto de la mujer. Manual de legislación sobre la violencia contra la mujer [Internet]. [Citado 23 de mayo de 2020]. Disponible en:

https://www.un.org/womenwatch/daw/vaw/handbook/Handbook-for-legislation-on-VAW-(Spanish).pdf

27. De Alencar-Rodrigues R, Cantera L. Violencia de Género en la Pareja: Una Revisión Teórica. 2012;43(1):11.

28. Joanna Briggs Institute . Joanna Briggs Institute reviewers' manual: 2014 edition. Australia: The Joanna Briggs Institute. 2014; [Internet]. [Citado 28 de agosto de 2019]. Disponible en: https://wiki.joannabriggs.org/display/MANUAL/JBI+Reviewer\%27s+Manual

29. Martínez León NC, García-Rincón L, Valencia D, Barreto S, Alfonso A, Quintero C, et al. Efecto de una intervención cognoscitivo conductual para el manejo de los celos en la relación de pareja. Psychologia Avances de la disciplina. [Internet] 2016;10(1):113-23.

https://doi.org/10.21500/19002386.2472

30. Ferrer-Perez VA, Ferreiro-Basurto V, Navarro-Guzmán C, Bosch-Fiol E. Programas de intervención con maltratadores en España: la perspectiva de los/as profesionales. Psychosocial Intervention. [Internet]. 2016;25(3):159-68. https://doi.org/10.1016/j.psi.2016.06.001

31. Gironés ML, Usaola CP. Intervención en Mujeres Víctimas de Violencia de Género. Experiencia de Psicoterapia Grupal en un Centro de Salud Mental Intervention for Women Victims of Domestic Violence. A Group Therapy Experience in the. Revista Clínica Contemporánea. [Internet]. 2014;5(1):29-39. https://doi.org/10.5093/cc2014a3

32. Vargas V, Lila M, Catalá-Miñana A. ¿Influyen las diferencias culturales en los resultados de los programas de intervención con maltratadores? Un estudio con agresores españoles y latinoamericanos. Psychosocial Intervention. [Internet] 2015;24(1):41-7.

http://dx.doi.org/10.1016/j.psi.2015.03.001

33. Matud MP, Padilla V, Medina L, Fortes D. Eficacia de un programa de intervención para mujeres maltratadas por su pareja. Terapia Psicológica. [Internet]. Diciembre de 2016;34(3):199208. http://dx.doi.org/10.4067/S0718-48082016000300004

34. Matud MP, Fortes D, Medina L. Eficacia de un programa de tratamiento psicológico individual para mujeres maltratadas por su pareja. Psychosocial Intervention. [Internet]. Septiembre de 2014;23(3):199-207. https://doi.org/10.1016/j.psi.2014.06.001

35. Aroca Montolío C, Ros Ros C, Varela Portela C. Program for the Prevention of Violence among Teenage Couples in the School Setting. Educar. [Internet] 16 de septiembre de 2015;52(1):11-31. https://doi.org/10.5565/rev/educar.673

36. Gupta J, Falb KL, Lehmann H, Kpebo D, Xuan Z, Hossain M, et al. Gender norms and economic empowerment intervention to reduce intimate partner violence against women 
in rural Côte d'Ivoire: a randomized controlled pilot study. BMC International Health and Humam Rights [Internet]. 2013 [citado 22 de agosto de 2019];13(1):26.

https://doi.org/10.1186/1472-698X-13-46

37. Abramsky T, Devries KM, Michau L, Nakuti J, Musuya T, Kyegombe N, et al. The impact of SASA!, a community mobilisation intervention, on women's experiences of intimate partner violence: secondary findings from a cluster randomised trial in Kampala, Uganda. J Epidemiol Community Health. [Internet]. Agosto de 2016;70(8):818-25. https://doi.org/10.1136/jech-2015-206665

38. Maya BM, Ortega-Rivera FJ, Jiménez VS. El DaViPoP: un programa de prevención de violencia en el cortejo y las parejas adolescentes. Apuntes de Psicología, . [Internet] 2013, 31 (11), 215-224.

39. Pérez RM, Giménez-Salinas Framís A, Espinosa J. Evaluación de la eficacia del programa de tratamiento con agresores de pareja (PRIA) en la comunidad. Psychosocial Intervention. [Internet] 2013;22(2):105-14. http://dx.doi.org/10.5093/in2013a13

40. Oliveira RNGD, Gessner R, Brancaglioni B de CA, Fonseca RMGS da, Egry EY. Preventing violence by intimate partners in adolescence: an integrative review. Rev. esc. enferm. USP [Internet]. 2016 Feb [cited 2019 Ago 13] ; 50( 1 ): 134-143.

http://dx.doi.org/10.1590/S0080-623420160000100018

41. Gómez JAM, Anacona CAR. Prevención de violencia en el noviazgo: una revisión de programas publicados entre 1990 y 2012. Pensamiento psicológico. [Internet] 2014;12(1):11732. https://doi.org/10.11144/Javerianacali.PPSI12-1.pvnr

42. Bolaños F, Hernández Castrejón A. Efectividad de las intervenciones en la violencia de pareja y ética. Rev. latinoam. bioet [Internet]. 21 de junio de 2018 [citado 12 de ago de 2019];18(35-2):33-1. https://doi.org/10.18359/rlbi.3380

43. Pérez VAF, Fiol EB. Las masculinidades y los programas de intervención para maltratadores en casos de violencia de género en España. Masculinidades y cambio social. [Internet]. 2016;5(1):28-51. DOI: http://dx.doi.org/10.17583/mcs.2016.1827

44. Lila M, Catalá A, Conchell R, García A, Lorenzo MV, Pedrón V, et al. Una experiencia de investigación, formación e intervención con hombres penados por violencia contra la mujer en la Universidad de Valencia: Programa Contexto. Psychosocial Intervention. [Internet]. 2010;19(2):167-79. https://doi.org/10.5093/in2010v19n2a8

45. Expósito F, Ruiz S. Reeducación de Maltratadores: Una Experiencia de Intervención desde la Perspectiva de Género. Psychosocial Intervention. [Internet]. 2010;19(2):145-51. Disponible https://doi.org/10.5093/in2010v19n2a6

46. Loinaz I, Echeburúa E. Necesidades Terapéuticas en Agresores de Pareja según su Perfil Diferencial [Therapeutic needs of partner-violent men according to their differential profile]. Clínica Contemporánea. [Internet]. 2010;1:85-95. https://doi.org/10.5093/cc2010v1 n2a2

47. Póo AM, Vizcarra MB. Diseño, Implementación y Evaluación de un Programa de Prevención de la Violencia en el Noviazgo. Terapia Psicológica. . [Internet]. Diciembre de 2011;29(2):21323. http://dx.doi.org/10.4067/S0718-48082011000200008

48. Jaramillo-Sierra AL, Ripoll-Núñez K. Adaptación de un programa de intervención para violencia situacional de parejas. Revista Estudios Sociales. . [Internet]. Octubre de 2018;(66):5570. https://doi.org/10.7440/res66.2018.06

49. Romero O, Penaranda C, Paredes M, Armbrister A. Como marcar tres dígitos reduce la violencia íntima de pareja en Medellín, Colombia [Internet]. Inter-American Development Bank; 2017 ago [citado 21 de agosto de 2019]. https://doi.org/10.18235/0000797

50. Guerrero MFR. Violencia física contra la mujer: una propuesta de abordaje desde un servicio de salud. Revista Cuidarte. [Internet] 2017;8(2):1656-67.

https://doi.org/10.15649/cuidarte.v8i2.404 
51. Wolfe DA, Crooks CV, Hughes R. La Cuarta R: Un Programa Escolar de Prevención de la Violencia en las Relaciones de Pareja en la Adolescencia. Psychosocial Intervention. [Internet] 2011; 20(2):193-200. http://dx.doi.org/10.5093/in2011v20n2a7

52. Vizcarra MB, Poo AM, Donoso T. Programa educativo para la prevención de la violencia en el noviazgo. Dating violence prevention program. Revista de Psicología Universidad de Chile. [Internet] 10 de enero de 2013;22(1):48-61. https://doi.org/10.5354/0719-0581.2013.27719

53. Fiol EB, Pérez VAF. Nuevo modelo explicativo para la violencia contra las mujeres en la pareja: el modelo piramidal y el proceso de filtraje. Asparkía: investigació feminista [online], 2013.Núm.24,p.54-67. Disponible en:

https://www.raco.cat/index.php/Asparkia/article/view/292174/380691 